\title{
Fight or flight? Behaviour and experiences of laypersons in the face of an incipient fire
}

\author{
Meinald T. Thielsch ${ }^{1}$, Julia Kirsch ${ }^{1}$, Hannah Thölking ${ }^{1}$, Lena Tangelder ${ }^{1} \&$ \\ Christoph Lamers ${ }^{2}$
}

${ }^{1}$ University of Münster, Department of Psychology, Fliednerstr. 21, 48149 Münster, Germany

${ }^{2}$ State Fire Service Institute NRW, Wolbecker Str. 237, 48155 Münster, Germany

Address for correspondence: Meinald T. Thielsch, University of Münster, Department of Psychology, Fliednerstr. 21, 48149 Münster, Phone: +49-251-83-38484, Fax: +49-251-8334190, Email: thielsch@uni-muenster.de, ORCID: 0000-0001-8493-9071

Funding: This work was supported by the German Federal Ministry of Education and Research (funding code FKZ 13N14208).

Data availability: The data of this study are available at https://doi.org/10.5281/zenodo.3753931

This is an Accepted Manuscript of an article published by Taylor \& Francis in "Ergonomics" on 26 Oct 2020, available online: http://www.tandfonline.com/10.1080/00140139.2020.1825824

Citation:

Thielsch, M. T., Kirsch, J., Thölking, H., Tangelder, L. \& Lamers, C. (2021). Fight or flight?

Behaviour and experiences of laypersons in the face of an incipient fire. Ergonomics, 64 (2), 149-170. https://doi.org/10.1080/00140139.2020.1825824 


\begin{abstract}
Within minutes, an incipient fire can develop into a life-threatening full fire. Consequently, it should be fought as early as possible. But are laypersons capable of doing this? In such a situation, how do they behave and feel? These questions are addressed in the current study. Persons without any professional firefighting training $(\mathrm{N}=64)$ were confronted in two experimental runs with a real incipient fire in the form of a burning pillow. The results show that most participants were motivated and able to extinguish the fire successfully. However, most of them made a number of mistakes. Of central importance for extinguishing the fire was self-efficacy. Furthermore, participants improved enormously in the second round, especially regarding reaction time span and various psychological variables (e.g., stress, mood). Particularly on the basis of these exercise effects, we can derive a number of practical implications.
\end{abstract}

Keywords: firefighting, laypeople, attitudes, self-efficacy, training effects

\title{
Practitioner summary
}

Laypersons are willing and able to successfully fight an incipient fire. Yet, their behaviour is not optimal and could lead to self-endangerment. Thus, it is critically important that people perform practical exercises as part of fire safety trainings and repeat them after some time. 


\section{Introduction}

Little empirical research exists on how laypeople behave when faced with fires. Most of the existing studies focus on matters of evacuation (e.g., Graham \& Roberts, 2000; Kobes et al., 2010; Tancogne-Dejean \& Laclémence, 2016) and on modelling and predicting human behaviour in evacuation situations (e.g., Gwynne, Galea, Lawrence, \& Filippidis, 2001; Kuligowski, 2013; Purser \& Bensilum, 2001). However, we do know that laypersons systematically underestimate the speed at which flames and smoke spread, and, thus, the danger posed by a fire (Purser \& Bensilum, 2001). As a result, those affected often realize too late that they are in danger (Tancogne-Dejean \& Laclémence, 2016). This can have devastating consequences, especially if people behave irrationally, such as attempting to retrieve personal property out of a burning room (Hall, 2004, Gerges et al., 2017). Yet, evacuation can also be problematic, as people tend to flee even through thick - and thus probably hot and toxic - smoke (Kobes et al., 2009; Proulx, 2001; Wood, 1972) or sometimes even jump out of a building unnecessarily instead of taking adequate shelter (Kobes et al., 2010).

Today, fires can be discovered at an early stage thanks to modern smoke detection systems ${ }^{1}$. In this initial phase, it would be possible for a layperson to fight the fire before it becomes seriously dangerous or can cause major damage. However, a dangerous full fire develops quickly: In modern buildings, a flashover ${ }^{2}$ can occur in less than five minutes (Kerber, 2012) - and injuries can be incurred before and without it, for example through inhalation of smoke or direct contact with the flames. This means that in the time it usually takes for the fire brigade to arrive, an incipient fire has most likely turned into a life-threatening full fire. Therefore, in the early fire phase, the people on site should assess the situation and, if possible without endangering themselves, attempt to extinguish the fire on their own.

Although results from surveys show that some people are motivated to fight a fire themselves (e.g., Gerges et al., 2017, Hall, 2004; Holborn et al., 2004; Wood, 1972), the recent literature offers no experimental investigations on the extent to which laypeople are capable of doing this, how they typically behave in the face of an incipient fire or how they feel about it. The present experiment is intended to close this gap.

\section{Incipient fires}

If a fire is extinguished by a layperson without the involvement of the fire brigade, it is likely that the fire was rather small or in the process of developing. But how do fires start in modern buildings? According to Holborn et al. (2004), ignition sources can be divided into two groups: whitegoods and cooking appliances on the one side (those are more likely to result in smaller fires) and electrical supply and lighting equipment, naked flames, candles and

\footnotetext{
${ }^{1}$ However, it must be noted that smoke detectors are not as effective if sited further away from the source of the fire (e.g. if the fire is in the kitchen, but the detector is placed outside this room with a closed door in between).

${ }^{2}$ A flashover is the nearly simultaneous ignition of most of the directly exposed combustible material in an enclosed area.
} 
smoking materials on the other side (those are more likely to produce larger fires). Recent fire statistics data from the $\mathrm{UK}^{3}$ also mention that the materials most often ignited first are food or cooking accessories; textiles, upholstery and furnishings; structure and fittings; paper and cardboard as well as rubbish and waste.

In the flashover, an incipient fire can suddenly develop into a full fire and thus endanger additional, previously uninvolved persons as well as rescue teams and can immensely increase material damage. Depending on the fire load and ventilation, the time of the flashover is often between 2 and 12 minutes (Kunkelmann \& Brein, 2010). In modern apartments, flashovers and lethal concentrations of fire gases can occur in under 3-5 minutes (Kerber, 2012; Kunkelmann, 2003). Since a flashover will most likely happen before the fire brigade arrives, it is all the more important that the person who discovers the fire reacts quickly and prevents the fire from spreading. Clearly, the time span between the emergence of the fire and the arrival of the fire brigade is enormously relevant for the lives and health of the people affected and the rescue teams.

\section{Human behaviour in the case of fire}

When a fire breaks out, the people affected have three main options for action: They can try to extinguish the fire themselves, escape from the building or seek shelter in the building and wait for rescue by the fire brigade (Kobes et al., 2010). Initial systematic research on human behaviour in the case of fire has been done by Wood (1972), who found that the most common first reactions to a fire were as follows: (a) investigate the fire (33\%), (b) warn others $(20 \%),(\mathrm{c})$ try to extinguish the fire $(13 \%),(\mathrm{d})$ prepare for evacuation $(10 \%),(\mathrm{e})$ ask whether the fire brigade has been alerted $(10 \%)$ and (f) call the fire brigade (6\%). Attempts to extinguish the fire by oneself were more commonly a second action and were less frequent the more dangerous the fire was perceived to be. Recent surveys found that typical reactions to fire alarms were to investigate, attempt to fight a fire or leave the building (Cordeiro et al., 2011; Gerges et al., 2017), whereas in surveys on typical reactions to smoke and fire, most respondents indicated that they would leave the building, and some stated that they would investigate the fire, ask for help, try to fight the fire or collect belongings (Cordeiro et al., 2011; Gerges et al., 2017). Based on data from 1993 to 1997, Hall (2004) reported that most people killed or injured by a fire were sleeping or trying to escape; others were unable to react, performed irrational actions, or attempted a rescue or fighting the fire themselves.

Despite the survey studies mentioned above, no detailed studies have been conducted on firefighting behaviour by laypeople, even though research from Australia and the UK (Barnett, Bruck, \& Jago, 2007) shows that the fire brigade is only called to every fourth house fire. Accordingly, Kobes et al. (2010) conclude that in the remaining cases, the fire either went out on its own or was extinguished by the occupants. In addition, several studies report that residents perform a substantial number of firefighting actions (e.g., Gerges et al.,

\footnotetext{
${ }^{3}$ See https://www.gov.uk/government/statistical-data-sets/fire-statistics-data-tables, particularly https://assets.publishing.service.gov.uk/government/uploads/system/uploads/attachment data/file/830426/f ire-statistics-data-tables-fire0603-120919.xlsx
} 
2017; Hall, 2004; Holborn et al., 2004). Overall, these findings indicate that laypeople are at least partially willing to extinguish a fire themselves and that a substantial number of fires might be extinguished by laypersons.

This is particularly true for dwelling fires, where initial responses to fire cues are carried out even quicker compared to other public building types (for an overview see Thompson et al., 2018). This may be interpreted as a consequence of the socio-physical environment: While feelings of ownership, control and responsibility (also towards loved ones) are high in the private space, a lack of a sense of responsibility and the fear of embarrassment often guide behaviour in public places, such as the workplace (Thompson et al., 2018). Here, the employer is obliged to bridge the diffusion of responsibility by establishing clear rules and processes, which must be formally laid out in a thoroughly developed safety management concept as required by law in many countries (e.g., Occupational Safety and Health Act, revised 2001 (US); Bauordnung für das Land Nordrhein-Westfalen, 2018 (Germany); The Regulatory Reform (Fire Safety) Order, 2005 (UK)). In order to guarantee the occupational safety and health of all employees, a holistic concept is required to ensure that the employer fulfils their legal obligation to keep the places where their employees work safe from occupational dangers and harm (Orazulike, 2015). Fire training and the maintenance of equipment are, among other things, essential when it comes to such fire safety management concepts (Baker, 2013).

\section{Intentions in the face of fire: Theory of Planned Behaviour and self-efficacy}

Since few empirical studies have been done on people's behaviour when confrontated with fire, the present study will apply the established psychological Theory of Planned Behaviour (TPB; Ajzen, 1985, 1991). The TPB has been empirically proven in numerous studies and meta-analyses over the past decades (see Armitage \& Conner, 2001; Steinmetz et al., 2016). Surprisingly, however, applications of the theory in the area of fire safety are rare. The few available published studies are on topics such as fire safety education (Byeon, 2019); firefighters' intentions to be physically active (Amodeo \& Nickelson, 2020); adolescents' intentions to engage in fire risk behaviours (Mentrikoski et al., 2019) or on predicting the intentions of fire department managers to implement safety recommendations (Welbourne \& Booth-Butterfield, 2005). However, to the best of our knowledge, the TPB has not yet been applied to predicting behaviour in a fire situation.

The TPB is based on the assumption that almost all human behaviour is based on a conscious or unconscious plan, and the plan is reflected in the intention of action. This intention to act arises from three motivational components: 1) the attitude towards a behaviour, 2) the subjectively perceived norm, and 3) the perceived behavioural control (see Figure 1). Therefore, people intend to carry out a behaviour if 1) they evaluate it positively, 2) they think that they are expected to show this behaviour, and 3) they themselves have the abilities and resources to carry out the behaviour. 


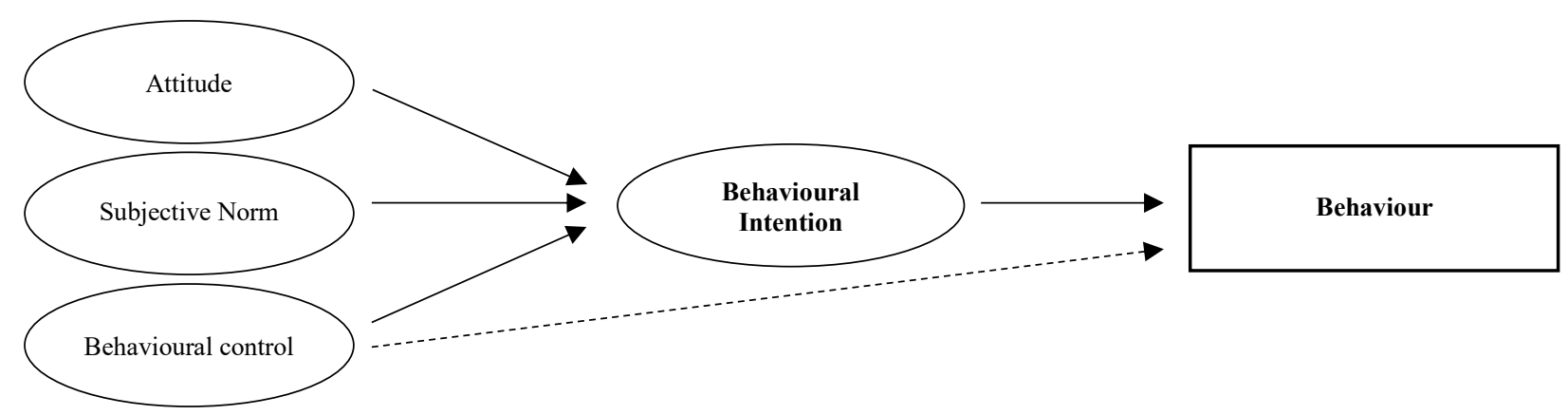

Figure 1. Theoretical model proposed in the Theory of Planned Behaviour (Ajzen, 1985, 1991).

The third component of TPB, perceived behavioural control, is of particular importance, since it not only influences intention to act but also directly influences behaviour (Ajzen, 1991). Ajzen (2002) describes perceived behavioural control as a superordinate construct that is composed of individual self-efficacy and the perceived general controllability of specific behaviour. Self-efficacy (Bandura, 1982) is generally described as a person's belief in his or her own competencies to successfully complete specific tasks. According to Bandura (1991), behaviour is largely motivated and regulated by continuous self-efficacy. Thus, self-efficacy is a central regulatory mechanism and influences human feeling and thinking, motivation and behaviour (Bandura, 1991). Even initial decisions in certain situations are influenced by the belief in one's own effectiveness, as people prefer to put themselves in situations they feel capable of dealing with. In addition, self-efficacy influences how much effort one invests and how persistent one is in overcoming obstacles (Bandura, 1977). Self-efficacy can thus be seen as a central predictor of behaviour, including people's behaviour when confronted with a developing fire. Accordingly, in the present study, we will also test the influence of selfefficacy on behaviour.

\section{Research questions and hypotheses}

The main question of our experiment is "How do people without professional firefighter training react to an incipient fire?" Therefore, we simulate an incipient fire in an everyday situation that, for example, could occur at a typical workplace. Here, a break room is to be simulated, as it could be found in various work contexts from classical office workplaces to kindergartens or schools. We aim to investigate whether laypeople are able to extinguish the incipient fire, how they behave and how they experience such a situation.

In our experiment, we vary the size of the incipient fire. In the first hypothesis (H1) we assume that a larger fire will increase participants' subjective stress and assessment of danger (see Kinateder, Kuligowski, Reneke, \& Peacock, 2014) and therefore be associated with a lower fire extinguishing engagement of participants (see Hulse et al., 2020). Based on the assumptions made in the TPB (Ajzen, 1985, 1991), we predict in the second hypothesis (H2) that when facing an incipient fire, participants with a stronger behavioural intention and higher behavioural control will be more likely to act and to start an extinguishing attempt. By 
adding self-efficacy as predictor of intention and behaviour, as self-efficacy closely related to behavioural control, we aim to test an extended TPB model. Thus, we assume a positive influence of self-efficacy on intention and behaviour with regard to extinguishing an incipient fire (H3). In addition, because some people are willing to take risks in the face of fire (as described above, e.g., by extinguishing or rescue attempts, see Gerges et al., 2017; Hall, 2004; Holborn et al., 2004), one's risk appetite could also be a personal variable that influences people's intentions of action. Thus, risk appetite will be investigated as a predictor of behavioural intentions, under the assumption that higher risk appetite is associated with higher intentions to extinguish a fire (H4).

Furthermore, we will study exercise effects caused by actual fire experiences (see Hulse et al., 2020): We expect that participants will show a stronger intention to extinguish an incipient fire after successfully finishing the experiment compared to an online pre-measure (H5). We also expect that after confronting an incipient fire, as compared to before, participants will have higher scores on the predictors of intention postulated in the TPB (Ajzen, 1985, 1991), namely attitude, the subjectively perceived norm, and the perceived behaviour control (H6). Additionally, we analyse specific exercise effects in the form of a second trial (see Byeon, 2019). We hypothesize that participants will feel less stressed and more satisfied with their behaviour in a second round (H7).

Finally, in an explorative manner we intend to analyse the effect of individual variables (e.g., personality, gender or age; see Bonny \& Leventon, 2020, Hulse et al., 2020) on participants' willingness to attempt extinguishing the incipient fire.

\section{Method}

The study results from a cooperation between the University of Münster with the State Fire Service Institute NRW (IdF NRW, "Institut der Feuerwehr NRW", the fire academy of the German state North Rhine Westphalia) and the German Fire Protection Association (vfdb, "Vereinigung zur Förderung des Deutschen Brandschutzes e. V."). It was conducted in a mixed multi-factorial and multivariate $2 \times 2$ design. In the experiment, the size of the fire was manipulated as the between-subjects variable, and the extinguishing attempt was repeated as the within-subjects variable. For dependent variables, we collected several measures of subjective experience as well as behavioural data (see below). The study was approved by the ethics committee of the Department 7 of the University of Münster (ID 2018-16-MT) and pre-registered with AsPredicted.org under the number 20436 (https://aspredicted.org/8py33.pdf).

In order to test and optimize the experimental setup and procedure, the study was piloted with six employees (office staff or similar without any firefighting experience) of the IdF NRW. Based on the pilot tests, the experimental setup was modified to be more realistic by adding further distractors (additional furniture, office supplies and decoration). Also, the original study design included the presence of a dummy as another between-subject condition, but the pilot tests revealed that this changed the correct solution approach and, thus, limited the 
comparability of reaction times between conditions. Therefore, the dummy condition was dropped, and the intended sample size of 80 participants decreased to 60 participants.

\section{Sample and recruiting}

Sample. The final sample consisted of 64 persons (63\% female). Participants' ages varied between 20 and 63 years $(M=33.84, S D=13.2)$. The majority of participants $(78 \%)$ stated the "Abitur" (German equivalent to "A-Levels") as the highest school-leaving qualification. Participants worked in the fields of education and schooling (27\%), administration (14\%), health $(9 \%)$, industry $(9 \%)$ and policing $(9 \%)$. A further $11 \%$ of the respondents were students of social subjects such as teaching or social sciences, and the remaining $20 \%$ did not identify with any of the above occupational groups (e.g., services, IT, crafts, catering, business).

Recruiting. The study was open to adults working in areas where laypeople could play a key role in fighting incipient fires, such as schools and kindergartens, nursing homes and hospitals as well as in the police force, industry or administration. Students who were close to graduation and would then work in teaching or a similar social profession were also invited. Potential participants were directly addressed or recruited via the platform PsyWeb (https://psyweb.uni-muenster.de). For ethical reasons, persons who were previously victims of fire were excluded from participation. A further exclusion criterion was current or previous membership in the fire brigade, as we were specifically investigating the behaviour of laypersons. Thus, as control variables, we recorded participants' experience with using a fire extinguisher and their participation in fire protection training. ${ }^{4}$

Of the 183 persons that opened the online screening questionnaire, 130 completed it (response rate $71 \%$ ). Based on the criteria explained above, 14 participants were excluded and 24 did not wish to be invited to the second part of the study. Thus, a total of 92 participants were invited to the experiment. Out of these, 25 did not respond to the invitation or cancelled due to scheduling reasons, leading to 67 persons that participated in the experiment. The final analysis included data from 64 person, since we learned that two of the participants met the exclusion criteria only after the experiment had been carried out, and one participant did not give informed consent to use their data. Participants received a compensation of $€ 50$ or were allowed to have their participation credited as working time.

\section{Measures}

In order to select participants based on exclusion criteria and to asses relevant psychological variables, potential participants were screened online using EFS Survey ("Enterprise Feedback Suite", provided by the Questback GmbH). In addition to demographic data, the survey assessed experience with fire prevention and membership in the fire brigade as well as the following psychological variables (in sum 79 questions, see the codebook, available at https://doi.org/10.5281/zenodo.3753931): intention of action (constructed by authors), attitude (based on Ajzen and Fishbein, 1980, and Mohiyeddini \& Bauer, 2007), subjective

\footnotetext{
${ }^{4} \mathrm{~A}$ total of 22 participants had experience using a fire extinguisher or were trained in fire protection. If a training course was attended, this was on average 4.56 years $(\mathrm{SD}=4.76)$ before the current experiment.
} 
norm (based on Mohiyeddini \& Bauer, 2007), perceived behavioural control (based on Mohiyeddini \& Bauer, 2007), self-efficacy (Beierlein et al., 2012), risk appetite (Beierlein et al., 2014), sensation seeking (Hoyle et al., 2002), organizational commitment (Felfe, Six, Schmook, \& Knorz, 2014), personality (Schupp \& Gerlitz, 2014) and a ranking of motives (Krumm et al., 2013). Between the two test runs, participants were asked to briefly state how stressed they were and how dangerous they considered the situation to be on a visual analogue scale (Lesage \& Berjot, 2011). Additionally, a short interview was conducted based on the "critical incident technique" (CIT, Flanagan, 1954). Participants were asked to answer six questions on the thoughts and feelings that arose while trying to extinguish the fire, whether or not they made a plan of action when confronted with the situation, which behaviours they would consider to be effective or ineffective and whether they could think of any alternative actions they could have taken. In the last question, participants were asked to assess the most important skills or qualities they believe someone needs to extinguish a small fire of this kind in real life (for exact question wording, see the codebook). The post-testquestionnaire again included scales of danger and stress assessment and, furthermore, examined mood (Jäger, 2004), general emotional state (Schallberger, 2005), satisfaction with their fire extinguishing attempt (constructed by authors), usability (Lewis et al., 2015), and a post-measure of the intention of action, attitude, subjective norms and perceived behavioural control using the same scales as in the pre-test. The post-test also included a manipulation check and the level of experienced reality. Unless explicitly stated otherwise in the appendix, a 7-point Likert scale ranging from "do not agree at all (1)" to "fully agree (7)" was used. Please find a detailed description of the scales used in the study in Appendix A.

\section{Procedure}

The experiment was carried out in two separate parts (see Figure 2): An online screening and the actual on-site experiments.

Online screening. The first part consisted of the online questionnaire described in detail above. At the end of the questionnaire, participants were asked to indicate if they would like to receive an e-mail invitation to the actual experiment. Participants who did not meet the inclusion criteria described above were not invited. The average response time for the online questionnaire was 12.90 minutes $($ median $=13.35)$.

Experimental trials. The fire extinguishing experiments were conducted on the training grounds of the IdF NRW. On the day of the actual experiment (typically some days after filling out the online screening), participants were first welcomed in the waiting room and informed about privacy (all instructions can be found in the codebook). Afterwards, they were led to the test site individually by the test supervisor. In front of the experimental setup (see Figure 3), the participant was asked to imagine being at their workplace. Then, they were instructed to enter the room once they heard a signal and react as they would in reality. While the participant was receiving these instructions outside the room, a pillow was set on fire. As soon as the a priori defined flame size (see Figure 4) was reached, the smoke alarm was triggered and the participant could enter the room. The trial was declared over once the participant left the room, the fire was completely extinguished, or the firefighter on standby 
had to intervene to prevent self-endangerment of the participant. A video example of a trial can be found at https://doi.org/10.5281/zenodo.3754003. After completion of the first trial, each participant underwent assessment of the perceived danger and their stress as well as mood, and they completed a short interview. After that, participants were instructed to imagine the same situation again. The second trial was carried out exactly like the first.

Afterwards, the test supervisor led the participant to a separate waiting room to complete the post-test questionnaire. Finally, the participant was debriefed ${ }^{5}$, thanked and remunerated. The tests lasted about 15 minutes (plus individual waiting periods before the start of the experiment, leading to a total of about 20 to 90 minutes).

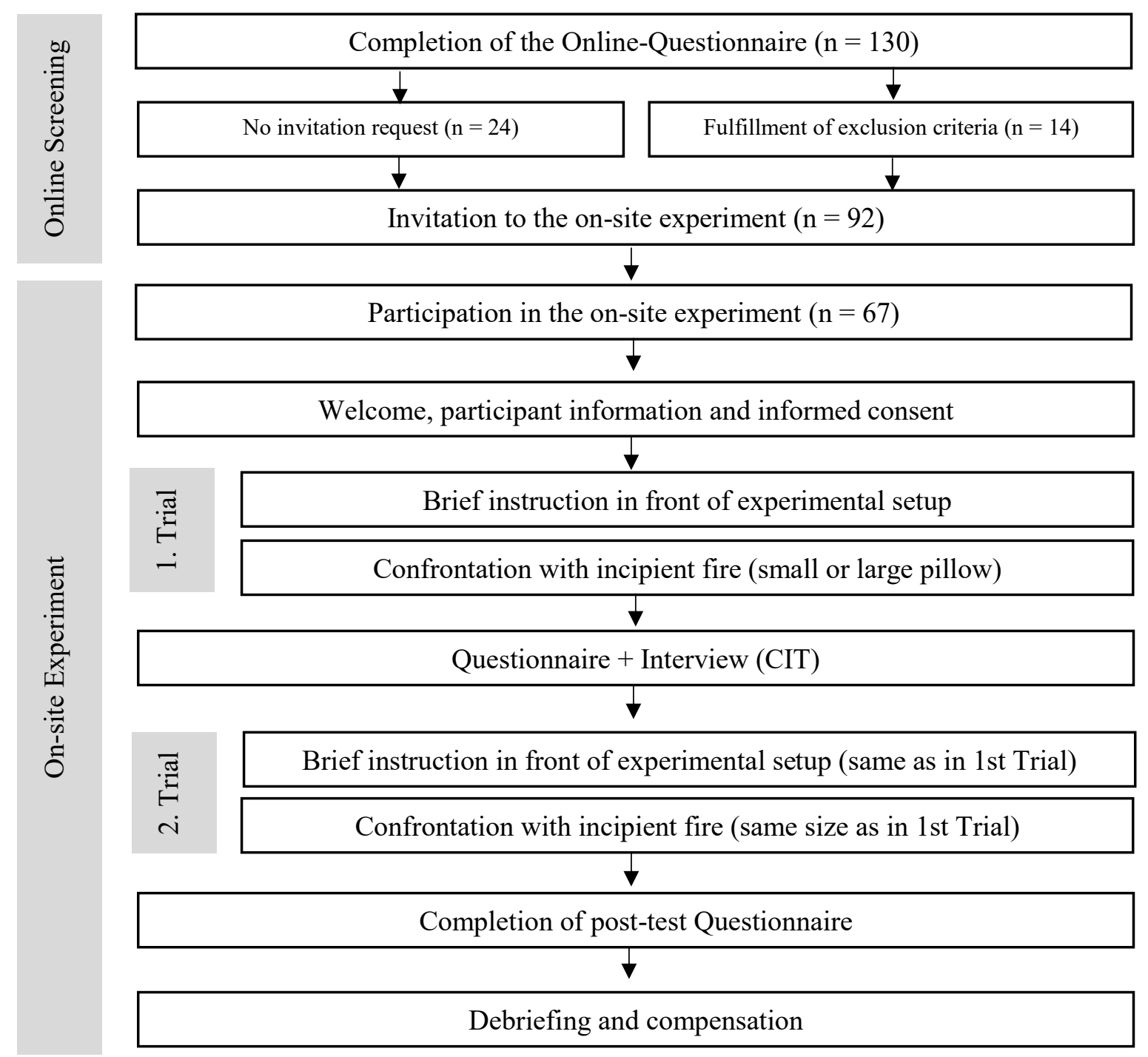

Figure 2. Flow chart of the experimental procedure.

\footnotetext{
${ }^{5}$ The formal debriefing following the post-test questionnaire included general information about the study, but no individual feedback on the performance during the extinguishing attempts. However, participants were free to wait until the end of the last trial of the day to receive tips and feedback by the firefighters (a number of participants took advantage of this opportunity). An exception was made for those participants whose attempt to extinguish the fire had to be interrupted due to self-endangerment. After the second trial, these participants received feedback from the firefighter present, explaining why their behaviour was selfendangering and how they should have proceeded alternatively.
} 
Experimental setup. The extinguishing trials took place in a room constructed of light and movable wall elements, which was intended to simulate the break room of a typical workplace (for photos of the original setup, see https://doi.org/10.5281/zenodo.3753987). In order to avoid harmful smoke development, the experimental room was constructed without a roof. However, the setup was protected from rain due to its position under a high canopy of an industrial building. The exact structure of the room is shown in detail in Figure 3: A camera (1) in the corner recorded the trials. To ensure the safety of participants, a firefighter (2) from the IdF NRW stood in a niche without being directly visible to participants. A small corridor led into the experimental room, which participants could enter through a regular door. Distractors (a computer (3) and a telephone (4)) as well as a fire extinguishing spray (5) were placed on a table next to the door (table 1). Another table (table 2) was set with dishes, a flower vase and magazines (6). This table also held the burning pillow (7), which was placed on a grill grid.

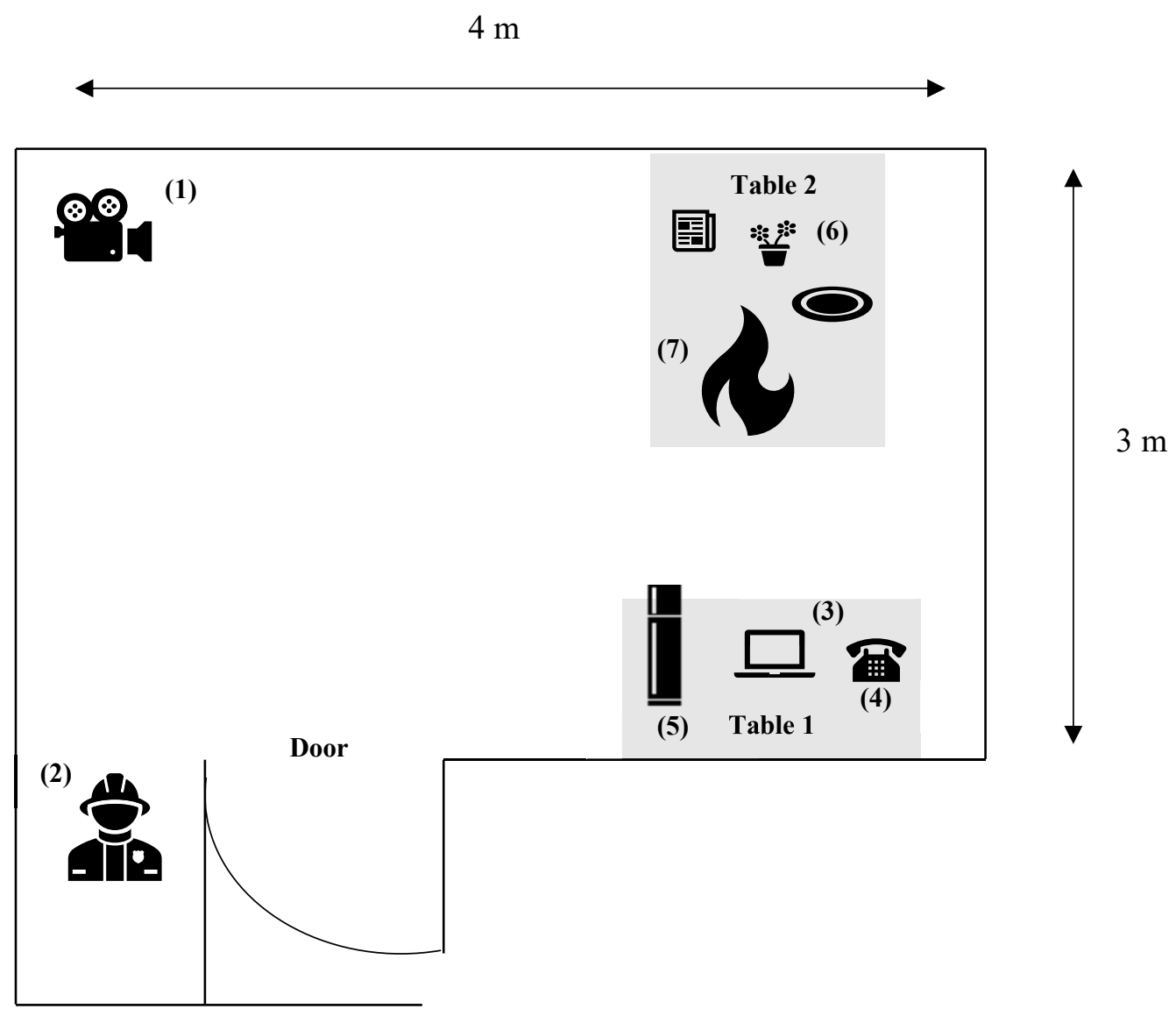

Figure 3. Experimental setup: (1) camera, (2) firefighter, (3) computer, (4) telephone, (5) fire extinguishing spray, (6) distractors (vase, magazines, dishes), (7) burning pillow.

Fire extinguishing spray. The "Prymos Universal Löschspray" (Prymos universal extinguishing spray provided by the Prymos $\mathrm{GmbH}$ ) for incipient fires, household \& kitchen, $625 \mathrm{ml}$ foam, was used in the experiment. According to the manufacturer, the patented Micro-Fog-Technology (MFT ${ }^{\circledR}$ ) enables laypeople to extinguish fires of class A (solid, mostly organic substances), B (liquid and liquefying substances) and F (edible oils and fats). The spray is classified according to an international standard system as $5 \mathrm{~A}, 21 \mathrm{~B}, 15 \mathrm{~F}$, 
wherein the numbers express the extinguishing capacity under standardized conditions in the individual fire classes. This classification makes the spray comparable to a smaller "classical" fire extinguisher filled with powder or foam.

Pillow. The pillow, which had a polypropylene filling, was ignited upon being placed on wooden pallets that were lit with a barbecue lighter. The small pillows were $40 \mathrm{~cm} \times 40 \mathrm{~cm}$ ( $240 \mathrm{~g}$ filling), and the large pillows were $50 \mathrm{~cm}$ x $50 \mathrm{~cm}$ (400 g filling). Figure 4 illustrates an exemplary fire course ( 90 seconds) for a small pillow.

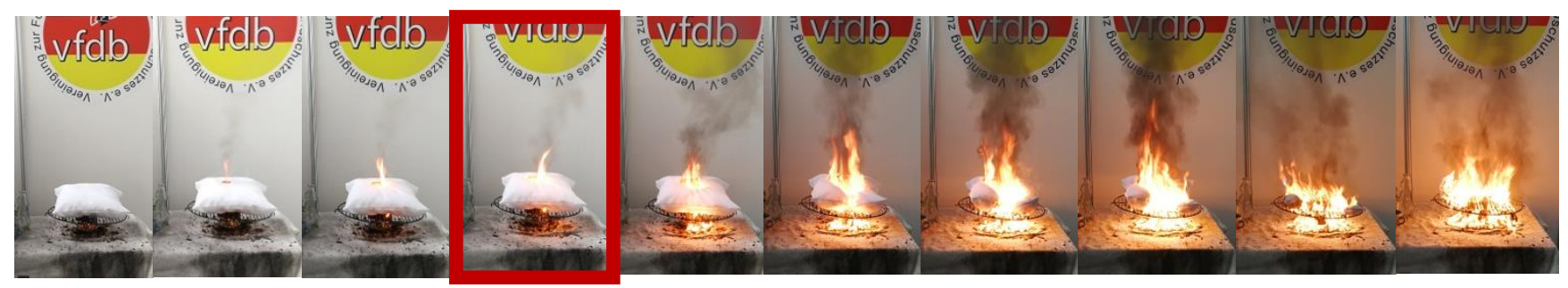

Figure 4. Time course (90 seconds) for a small burning pillow. The time interval between each picture is about 10 seconds. The alarm sounded when the fire size was similar to the size of the fire in the framed image.

\section{Results}

\section{Manipulation check}

To test the fire size manipulation, we compared the mean values of the item "I perceived the fire I was confronted with as large". However, no significant differences were found between subjects with a small pillow $(M=2.38, S D=1.27)$ and subjects with a large pillow $(M=$ $3.14, S D=1.67)(t(49.32)=0.82, p=.20)$. In addition, we checked whether the size of the pillow was related to the actual fire size. We found no significant correlation of the pillow size with the size of the fire when the alarm started (1. Trial: $r=-.03, p=.82 ; 2$. Trial: $r=-$ $.09, p=0.47$ ) nor with the fire size at the beginning of the extinguishing process (1. Trial: $r=$ $.18, p=.18 ; 2$. Trial: $r=-.16, p=.21)$. Since the experimental manipulation of the pillow size was not connected to the objective or subjectively perceived size of the fire, we were not able to test our first hypothesis (H1) on effects of the fire size - and from here on both groups were jointly analysed.

In order to evaluate the validity of the results, we assessed whether participants perceived the experimental setup as realistic. Furthermore, they were asked to assess how realistic it seemed for them to be confronted with a similar situation at their workplace. A total of $74 \%$ of the participants agreed with both statements from "rather" [=5] up to "completely" [=7] (average of both items: $\mathrm{M}=5.42, \mathrm{SD}=1.33$ ). This indicates the experiment had a high degree of perceived realism. 


\section{Behaviour of participants}

When first confronted with an incipient fire, $95 \%$ of participants attempted to extinguish it. In the second trial, this value increased to $97 \%$; however, this increase was not significant $(t(63)$ $=-0.57, p=.09$ ). What was significant was the increase in number of participants who relied solely on the fire extinguishing spray in the second trial $\left(\chi^{2}(1)=4.01, p<.05\right)$. Table 1 shows the initial reactions of participants in both trials, according to the options given for action.

\section{Table 1: Reactions according to possible courses of action}

\begin{tabular}{lcc}
\hline & Trial 1 & Trial 2 \\
\hline $\begin{array}{l}\text { (a) Extinguishing attempt with fire } \\
\text { extinguishing spray }\end{array}$ & $81 \%$ & $86 \%$ \\
$\quad-\quad$ Extinguishing spray only & $66 \%$ & $81 \% *$ \\
$-\quad$ Extinguishing spray first plus different & $11 \%$ & $2 \% *$ \\
$\quad$ method & & \\
$-\quad$ Emergency call first plus extinguishing & $5 \%$ & $3 \%$ \\
$\quad$ spray & $14 \%$ & $11 \%$ \\
(b) Extinguishing attempt with different & & $5 \%$ \\
method & $5 \%$ & $3 \%$ \\
$\quad-\quad$ Stifling fire with magazines & $3 \%$ & $3 \%$ \\
(c) Escape from the room & $5 \%$ & $3 \%$ \\
(d) Only send out an emergency call & $2 \%$ & - \\
\hline
\end{tabular}

Note. All values rounded. Others = Removing the grate with a magazine; clearing the table to extinguish fire with tablecloth. A chi-squared test of independence was calculated comparing the frequency of the particular actions taken in trial 1 vs. trial 2 . Significance: $* p<.05$

Table 2 shows details of the extinguishing procedure and expert recommendations for action according to the fire brigade (see https://doi.org/10.5281/zenodo. 3754003 for a video example of an expert using the spray). With the exception of exploratory behaviour, a very similar reaction pattern was observed: The majority of participants closed the door behind them, assumed a high posture and aimed at the flames when extinguishing. According to experts, however, precisely this reaction pattern is not recommended. Regarding the situation presented here, experts advise people to leave the door open, if only to allow for a quick escape route. ${ }^{6}$ Concerning exploratory behaviour, experts advise that for almost all cases of fire, performing a comprehensive assessment of the situation is indispensable (e.g., Plattner, 2004, p. 134f). For extinguishing a fire, people should assume a bent body position and direct the jet at the incendiary material, not at the flames (Rodewald \& Rempe, 2005, p. 144; Schott \& Ritter, 2018 p. 242f, and, most comprehensively, Höffchen \& Lücking, 2005, p. 185ff). During the interview after their first attempt, when participants were directly asked what could be considered effective behaviours, many referred to using the fire extinguisher spray, having a quick reaction and performing explorative behaviour. As ineffective behaviours,

\footnotetext{
${ }^{6}$ In general, it is controversially discussed in fire service when it is useful to leave doors open or not for indoor firefighting (Cimolino et al., 2018, p. 161f; Pulm, 2018, p. 94ff for Germany).
} 
participants mentioned having difficulties with the fire extinguisher spray, not recognizing it or acting too slowly (see Appendix E).

Table 2: Categorization of displayed behaviour during extinguishing attempt

\begin{tabular}{|c|c|c|}
\hline Behaviour & Trial 1 & Trial 2 \\
\hline \multicolumn{3}{|l|}{ Closing the door } \\
\hline Yes & $87 \%$ & $91 \%$ \\
\hline $\mathrm{No}^{1}$ & $13 \%$ & $9 \%$ \\
\hline \multicolumn{3}{|l|}{ Exploratory Behaviour } \\
\hline Exploring the situation ${ }^{1}$ & $50 \%$ & $17 \% * * *$ \\
\hline Determinedly approaching the fire & $50 \%$ & $83 \% * * *$ \\
\hline \multicolumn{3}{|l|}{ Posture during extinguishing attempt } \\
\hline High & $92 \%$ & $87 \%$ \\
\hline Low $^{1}$ & $8 \%$ & $13 \%$ \\
\hline \multicolumn{3}{|l|}{ Extinguishing target } \\
\hline Incendiary material $^{1}$ & $12 \%$ & $9 \%$ \\
\hline Flames & $88 \%$ & $91 \%$ \\
\hline
\end{tabular}

Notes. All values rounded. N's vary between 50 and 64 due to missing data caused by different behaviours; ${ }^{1}$ indicates the correct procedure according to expert ratings. A chi-squared test of independence was calculated comparing the frequency of the particular actions taken in the 1 vs. 2 trial. Significance: ${ }^{*} p<.05,{ }^{* *} p<.01,{ }^{* * *}$ $p<.01$

The reaction time span (time between entering the room and starting the attempt to extinguish the fire) decreased significantly from an average of 17.93 seconds (median $=17.50 ; S D=$ 10.17; $\min =2 \mathrm{sec}$.; $\max =48 \mathrm{sec}$.) in the first trial to an average of 12.07 seconds (median $=$ 11.50; $S D=4.15 ; \min =5 \mathrm{sec}$.; $\max =24 \mathrm{sec}$. $)$ in the second trial $(t(59)=4.70, p<.001, d=$ $.60)$. The effect size can be considered as medium (Cohen, 1988) ${ }^{7}$. During this reaction time span, in the first trial on average one second (median $=1.00 ; M=2.5 ; S D=3.30 ; \min =0$; $\max =12$ ) was spent reading the instructions for using the spray. In the second trial, participants mostly did not read the instructions at all (median $=0.00 ; M=0.51 ; S D=1.27$; $\min =0 ; \max =6 ; t(48)=5.13, p<.001, d=.73)$. Extinguishing the burning pillow with the spray took participants on average 13.57 seconds (median $=10.00 ; S D=8.29 ; \min =2 \mathrm{sec}$; $\max =38 \mathrm{sec}$.) in the first trial and 13.65 seconds (median $=11.00 ; S D=10.63 ; \min =3 \mathrm{sec}$; $\max =55 \mathrm{sec}$.) in the second trial; the time difference in applying the spray was not significant $(t(91.90)=-0.04, p=.48)$.

\footnotetext{
${ }^{7}$ According to Cohen (1988), an effect size between $d=.20$ and $d=.50$ can be interpreted as small, whereas an effect size between $d=.50$ and $d=.80$ can be considered medium. An effect exceeding the value of $d=.80$ can be classified as large.
} 


\section{Explaining participants' behaviour}

We aimed to explain participants' behaviour using the Theory of Planned Behaviour (TPB, see $\mathrm{H} 2$ ), extended with the variables self-efficacy (H3) and risk appetite (H4). First, we examine predictors of behavioural intentions, then we look at the prediction of the behaviour itself.

Predicting intentions. A multiple regression model was used to examine whether the determinants of intention towards a certain action postulated in the TPB as well as selfefficacy and risk appetite actually affect one's general intention to extinguish an incipient fire. Therefore, we used the data from the online pre-test. While attitude, subjective norm and behavioural control show a significant correlation with the criterion (see Appendix B), only the attitude towards extinguishing incipient fires significantly explains variance of the intention $(\beta=0.38, p<.05)$. All predictors together explain $27 \%$ of the variance in the criterion "intention to actively attempt to extinguish an incipient fire" $(F(5,56)=4.04, p<$ $.01, f^{2}=.36^{8}$ ) (see Appendix D). Thus, with regard to intentions, hypotheses 3 and 4 were not confirmed.

Predicting behaviour. In the interview, $80 \%$ of participants $(n=51)$ stated that they made a plan before the extinguishing attempt, mostly about exploring the situation and using the fire extinguisher spray (see Appendix E).

To test how intention translated into behaviour, we calculated a regression analysis using the behavioural data from the experiment. We aimed to predict behaviour using the intention and behavioural control (as postulated in the TPB; see H2), and, additionally, using self-efficacy (as postulated by Bandura, 1991; see H3). As the binary variable "fire extinguishing attempt" shows a ceiling effect, the criterion "reaction time span" was used instead to test these theoretical assumptions. The results of the multiple linear regression show that this model was able to account for $16 \%$ of the variance of the reaction time span $\left(R^{2}=.16, \mathrm{~F}(3,54)=\right.$ $3.49, p<.05)$, the effect is considered small $\left(f^{2}=.19\right.$; Cohen, 1988). In the model, only selfefficacy turned out to successfully predict behaviour. If self-efficacy beliefs increased by one unit, the reaction time span decreased by 3.66 seconds $(\beta=-3.66, S E=1.73, \mathrm{p}<.05)$. The direct path assumed in the TPB between behavioural control $(\beta=-0.45, S E=1.29, p=.73)$ as well as intention to extinguish the fire $(\beta=-2.40, S E=1.46, p=.11)$ and behaviour (quantified here as a reaction time span) was not significant in the present analysis (see Figure 5 for a summary of results). Thus, with regard to behavioural outcomes, hypothesis 2 was not confirmed, whereas hypothesis 3 was.

\footnotetext{
${ }^{8}$ According to Cohen (1988), the effect size of a multiple regression can be considered small between $f^{2}=.02$ and $f^{2}=.15$. An effect size below $f^{2}=.35$ may be interpreted as medium, while everything above is considered a big effect.
} 


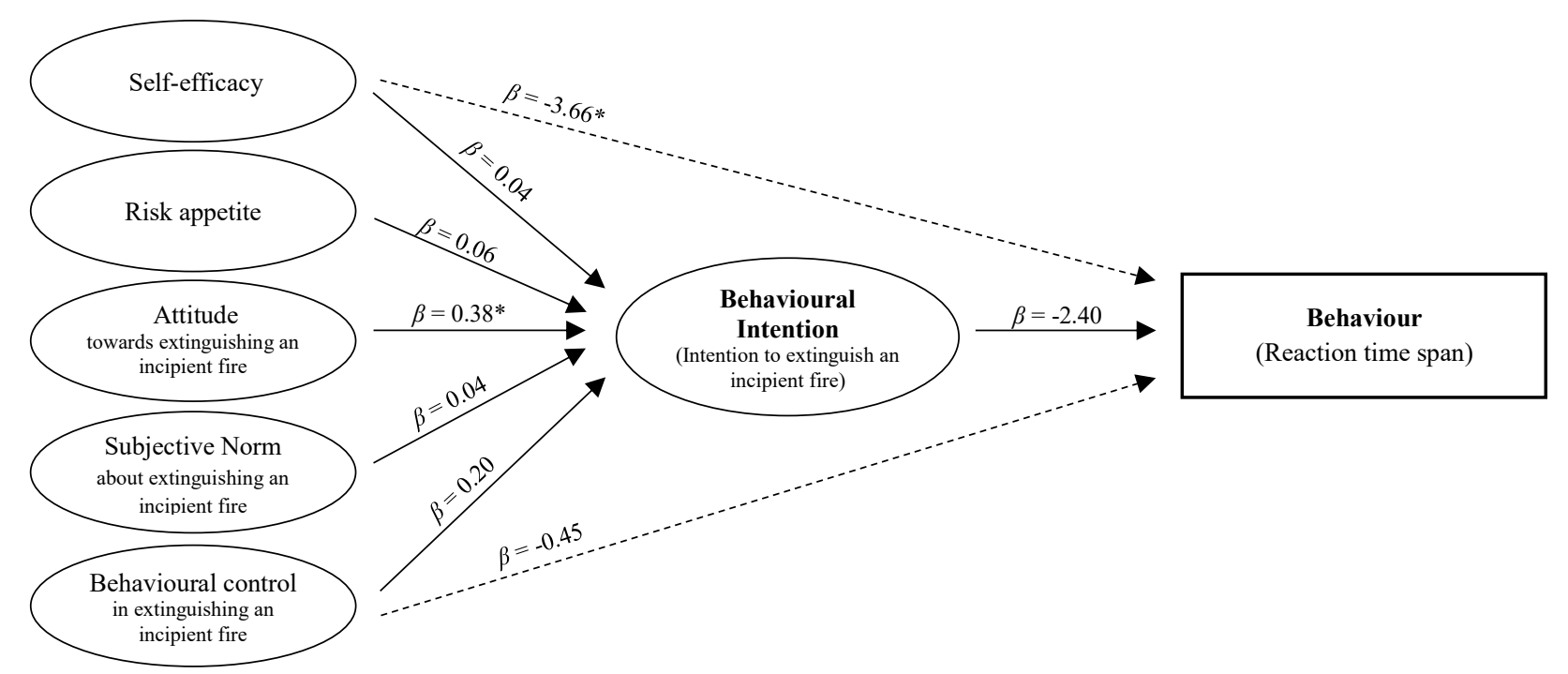

Figure 5. Summarized results of the two regression analyses conducted to validate the assumed model. $\beta=$ beta weights of the predictors. Significance: $* p<.05$.

\section{Experiences of the participants and exercise effects}

In the interviews after the first trial, the emotional responses were divided: While several participants felt secure and satisfied, others expressed uncertainty and stress, some even fear (see Appendix E). In order to examine the psychological experience of participants more closely, we assessed mood, satisfaction as well as the perceived danger and stress of the situation after each trial. Results are displayed in Table 3. As hypothetically assumed (H7), mood and satisfaction improved (with small effect size) while perceived danger and stress decreased significantly (with small and medium effect size, respectively). Additionally, the general emotional state of participants was assessed after the second trial. Participants felt significantly more positively $(M=5.73, S D=0.66)$ than negatively activated $(M=2.92, \mathrm{SD}$ $=1.16 ; t(54)=15.48, p<.001)$. 
Table 3: Participants' psychological experiences (means, standard deviations, results Welch Two Sample t-test and Cohen's d)

\begin{tabular}{|c|c|c|c|c|c|c|c|}
\hline & \multicolumn{2}{|c|}{ 1st Trial } & \multicolumn{2}{|c|}{ 2nd Trial } & \multirow[b]{2}{*}{$t(63)$} & \multirow[b]{2}{*}{$p$} & \multirow[b]{2}{*}{$d$} \\
\hline & $M$ & $S D$ & $M$ & $S D$ & & & \\
\hline Mood & 3.97 & 0.64 & 4.23 & 0.77 & 2.80 & $<.01 * *$ & .35 \\
\hline Satisfaction & 5.38 & 1.54 & 6.03 & 1.15 & $3.10^{\dagger}$ & $<.01 * *$ & .39 \\
\hline Perceived danger & 3.43 & 2.21 & 2.70 & 2.28 & 3.17 & $<.01 * *$ & .40 \\
\hline Perceived stress & 3.54 & 2.30 & 2.24 & 1.85 & 4.57 & $<.001 * * *$ & .57 \\
\hline Attitude & 4.31 & 0.71 & 5.83 & 0.62 & $16.76^{\dagger \dagger}$ & $<.001 * * *$ & 2.13 \\
\hline Subjective norm & 5.26 & 1.12 & 5.68 & 1.10 & -3.21 & $<.01 * *$ & .40 \\
\hline $\begin{array}{l}\text { Behavioural } \\
\text { control }\end{array}$ & 5.24 & 1.12 & 5.98 & 0.82 & $6.27^{\dagger \dagger \dagger}$ & $<.001 * * *$ & .80 \\
\hline $\begin{array}{l}\text { Intention to } \\
\text { extinguish }\end{array}$ & 6.31 & 0.94 & 6.46 & 0.82 & $-1.13^{\dagger}$ & .31 & .17 \\
\hline
\end{tabular}

Exercise effects. In comparing the pre- and post-test questionnaires, participants' intention to actively extinguish an incipient fire when confronted with one changed only descriptively (see Table 3) but was not significantly higher as assumed in hypothesis 5. Nevertheless, participants' intention to react passively (keep a safe distance or make an emergency call) was significantly lower after the experiment (Pre: $M=3.8, S D=1.48$; Post: $M=3.15, S D=$ $1.42 ; t(62)=3.47, p<.001, d=.44)$; the effect size of this difference is small. Furthermore, in line with our assumptions (H6), all determinants of intention postulated in the TPB improved significantly from pre- to post-test (see Table 3 ). With an effect size of $d=2.13$, the effect of participating in the experiment on participants' attitudes towards extinguishing an incipient fire can be considered particularly large.

\section{Explorative analysis}

As stated in the pre-registration, the originally intended main dependent variable was the behaviour of laypersons when confronted with the incipient fire. However, since the experiment revealed a ceiling effect in this variable (95\% and $97 \%$ of participants started an extinguishing attempt in the first and second trials, respectively), not all of the exploratory analyses originally intended were carried out. Instead, we selected individual variables for which further effects are conceivable based on the results reported above and where significant correlations were found in the correlation matrix of study variables (see Appendix B) - namely gender, age, and past participation in fire safety trainings. Finally, we report on participants' short evaluation of the fire extinguisher spray. 
Gender effects. As shown in Table B.1 in the appendix, gender had a correlation of $r=-.25$ ( $p$ $<.05$ ) with perceived danger after the first trial. Thus, in order to investigate possible gender effects, a MANOVA was used to investigate whether men and women differ with regard to the variables already discussed above (i.e., intention to extinguish an incipient fire, intention not to actively extinguish an incipient fire, attitude, subjective norm, perceived behavioural control, self-efficacy, risk appetite, mood, perceived stress, perceived danger, satisfaction, reaction time span). As the MANOVA revealed no significant overall effect of gender $(F(17$, $40)=1.25, p=.27)$, no specific univariate comparisons were made.

Regression models under consideration of possible confounding variables. As described above, $n=22$ participants had experience using a fire extinguisher or participated in a fire protection training (on average 4.56 years ago). Since the correlation matrix of study variables (see Appendix B) showed correlations between such prior training and intention ( $r$ $=.38, p<.01)$ as well as age and intention $(r=.38, p<.01)$, these variables as well as gender ${ }^{9}$ were included in the regression models described above in order to check whether these covariates affected the obtained results.

The first model was tested using intention as a criterion and integrating the three confounding variables described above (past training, age, and gender) as well as the three predictors postulated in the TPB (attitude, subjective norms, and perceived behavioural control stated in the pre-test) plus self-efficacy and risk appetite. The resulting model can explain $40 \%$ of variance $\left(R^{2}=.41, \mathrm{~F}(8,53)=4.51, p<.001\right)$. The effect size of the entire model was $f^{2}=.68$ and can, thereby, be considered as large (Cohen, 1988). In this model, only training $(\beta=0.58$, $S E=0.27, p<.05)$ significantly predicted someone's intention to extinguish an incipient fire when confronted with it.

Parallel to the analyses outlined above, we also tested whether the additional variables influence the direct prediction of behaviour with self-efficacy, behavioural control and intention towards behaviour. A model in which past training, age and gender are also integrated can explain $22 \%$ of variance in the criterion "reaction time span" $\left(R^{2}=.22, \mathrm{~F}(6,51)\right.$ $=2,43, p<.05)$. The effect size of the entire model was $f^{2}=.29$, which can be considered medium (Cohen, 1988). As before, as a single predictor, only self-efficacy significantly predicted a change in behaviour $(\beta=-3.97, S E=1.73, p<.05)$.

Evaluation of the spray. After the two trials, participants who used the fire extinguishing spray stated that they were "rather satisfied" $(M=5.79, S D=0.99)$ with the product. The usability was rated very high $(M=6.54, S D=0.84)$. Further, participants did not agree with the statement "I would use a fire extinguisher instead of the fire extinguisher spray" $(M=$ 3.07, $S D=1.78)$.

\footnotetext{
${ }^{9}$ There were no significant differences between men and women regarding participation in fire safety training $\left(\chi^{2}(1)=0.8, p=.37\right)$.
} 


\section{Discussion}

With regard to our main research question our results clearly show that even laypeople are principally motivated to fight an incipient fire - and that they are quite successful at it. This finding is in line with assumptions from earlier work (e.g., Kobes et al., 2010), but here we tested it experimentally for the first time with laypersons confronted with a real fire. However, from an expert point of view, most participants made a number of mistakes that could lead to a high degree of self-endangerment (cf. Hall, 2004). Particularly to mention is the extinguishing behaviour itself (extinguishing the flames and not the combustible material) as well as participants' lack of considering an escape route. Both errors were committed by about $90 \%$ of the test persons in both trials (see Table 2). Moreover, the interviews showed that the persons were not even aware of such mistakes.

This underlines both the importance of training of laypersons as well as the importance of reacting quickly to an incipient fire at a stage when it is not yet dangerous (either due to smoke or heat). With respect to training, we identified many positive effects by simply carrying out a practical extinguishing attempt twice:

- Participants' attitudes towards making an extinguishing attempt increased, as did their experienced control (with large effect size; confirming hypothesis 6);

- Their stress experiences decreased (with medium effect size; confirming hypothesis 7);

- Participants consider it more strongly as a subjective norm to extinguish a small fire themselves, and their perception of danger decreased while their satisfaction and mood increased (with small effect sizes in each case; confirming hypotheses 6 and 7);

- Above all, participants' reaction times (from entering the room to the beginning of the extinguishing attempt) decreased substantially by one-third, from an average of $\sim 18$ seconds in the first trial to $\sim 12$ seconds in the second trial.

At this point, we must emphasize that in this study participants received no specific fire safety training; they only had a second attempt at extinguishing the fire. This illustrates the great benefit of practical exercise (as known from professional firefighter trainings, see Sommer \& Nja, 2011) and the advantage of having actual fire experiences (see Hulse et al., 2020). Also, the results clearly show that such a situation requires a few seconds for participants to orient themselves and prepare the extinguishing agent. With that in mind, the time reduction found in the second trial can be seen even more positively.

Furthermore, our results show that to react quickly, people must have the confidence that they can act appropriately, i.e., they must have a high self-efficacy. This finding underlines the importance of self-efficacy for human behaviour (as postulated by Bandura, 1991, and thus included in our hypothesis 3). Moreover, in our data, self-efficacy was the only significant factor in predicting behaviour (in terms of reaction time). Thus, while results were in line with hypothesis 3 , hypothesis 2 (influence of intention and behavioural control) was not confirmed. For our participants, the intention to act in the event of fire was already high 
in the pre-test, and was mainly positively influenced by attitude and past training (and not by the experiment itself, as assumed in hypothesis 5). Yet, while the connection between this intention and actual behaviour points in the expected direction, it was not statistically significant. While this finding follows previous research, in that intentions are associated with behaviour but do not automatically lead to the execution of an action (see research in the so called "intention-behaviour-gap", Rhodes \& De Bruijn, 2013), it can also be discussed in terms of our study's limitations, which could, at the same time, offer promising avenues for future research.

\section{Limitations and future research}

With regard to the role of intentions and the application of the TBP model, the present analysis is limited by the unexpected ceiling effect found in the participants' behaviour. Thus, since almost all participants made attempts to extinguish the fire, there was little variance in responses, and we could not fully test the extended TBP model. Based on our data, hypotheses 2, 4 and 5 are to be rejected completely, hypothesis 3 partially (with regard to the influence of self-efficacy on intentions). Nevertheless, it is advisable to check them again in the future, preferably with data that do not show such a strong ceiling effect.

Further, due to the high experimental effort, the sample size in the present study was limited, so that separate regression analyses had to be applied. From a methodological point of view, it would be better to apply a structural equation model for testing the indirect effect of behavioural control, attitude and subjective norm on behaviour, mediated by intention. However, when assuming small to medium effect sizes of the direct paths and a full mediation of the effect by intention, achieving a power of .8 would require a sample size of at least 405 (Fritz \& MacKinnon, 2010), which was technically not feasible with the given resources in the current study. Nevertheless, it would be worthwhile to try to carry out this optimal model check in the future; for example, data from several similar studies in this context could be combined.

A similar situation applies to the originally planned exploratory analyses: A causal relationship between the reaction time span (as an alternative measure of behaviour) and factors such as facets of personality is, in our view, theoretically not plausible and was therefore not analysed. However, since there is some evidence for the relevance of personality factors for professional firefighters (e.g., Szrajda et al., 2017; Wagner et al., 2009), it might be interesting for future research to examine such variables and their relationship to more general patterns of laypersons' behaviour.

In general, the observed ceiling effect might be partly caused by certain demand characteristics of the test situation: Although the participants did not receive any specific information in advance, and the fire test started right at the beginning of the experiment, it took place on a training ground of the IdF NRW fire academy. This may have aroused certain suspicions in individual participants. Furthermore, even though interviews were highly standardized, and a subsequent check of the interview transcripts revealed no explicit hints by the interviewers, we cannot completely exclude the possibility that implicit feedback and cues were perceived by participants in the short interview between the trials. Nevertheless, the manipulation check was successful, as the situation was experienced as realistic, and 
many subjects reported feelings of insecurity, stress and fear after the first run (see Appendix E). This argues against the idea that the experimental situation was too straightforward. In the present study a working context was simulated, which in practice differs from private dwellings: on the one hand, by clearer structures and safety concepts for fire protection, but also, on the other hand, by a lower familiarity and attachment to the building and the persons and objects in it (see Thompson et al., 2018). Future studies could further explore these different settings; based on our experimental experiences and because of the aforementioned high level of personal attachment, we would assume that people in a private environment would attempt to extinguish a fire at least to a similar extent as in our study. At this point it must also be said that although the participants in the present study were asked to imagine a break room at their workplace, this type of room does not differ from a private room to the same extent as, for example, an industrial workplace in production.

Additionally, the realistic quality of the experiment is important for future studies, particularly with respect to the size of the incipient fire. Since we had no information beforehand, the fire condition used two different sizes of a pillow (as according to statistics, textiles, upholstery and furnishings are typical ignition sources). We learned that fires produced by pillows of different sizes were perceived very similarly - which prevented testing hypothesis 1 . Thus, if a bigger fire is to be simulated, future studies might use larger objects or allow the fire to spread, to some degree, to another nearby object. Importantly, this should be carefully planned and pre-tested, given the emotional response of some of the participants in the present study as well as the potentially higher risk of self-endangerment (particularly as people tend to underestimate the risks posed by larger hazards, see Hulse et al., 2020).

Finally, the present study did not compare different extinguishing agents that could be used by laypersons. Companies have various extinguishing agents at their disposal which could be integrated into fire protection management concepts (in addition to the sprays tested in this study, employers can provide fire blankets, traditional fire extinguishers and, in some cases, wall-mounted fire hoses designed to be operated by laypersons). A direct comparison of different extinguishing agents by laypersons with regard to usability would be an interesting topic for future research. Thereby, the extinguishing performance of the participants (i.e., the reaction timespan) and their reactions in the first trial would be of particular interest. Such an experiment could provide information about the most intuitive and best usable available devices. This would be particularly relevant for organisations that do not have the resources to ensure regular training with different extinguishing agents for all their staff.

\section{Practical implications}

The main practical implication is the clear positive effect of even simple training (in our study the practical application of an extinguishing agent in two runs) on improving laypersons' behaviour when fighting an incipient fire. The present findings, particularly from the interviews with participants, highlight several important aspects for planning such trainings, which ought to be conducted regularly as part of a holistic fire safety management concept in companies. 
First, it is of prime importance to offer practical exercises that can be repeated after some time. Repetition is central, as some participants in our study reported having participated in earlier trainings, and this had a positive effect on their attitude towards fighting an incipient fire. However, as this training was held, on average, almost five years ago, this did not lead to a significantly better performance in the present study. Moreover, insufficient or too long-ago training might, in the worst case, even result in people having a higher intention to extinguish a fire, but then potentially endanger themselves more because of incorrect behaviour.

Second, laypersons have to learn how to judge the risk resulting from an incipient fire. It is crucial that they fight the fire as early as possible not only in case of a dwelling fire but also in an organisational setting - and choose strict evacuation processes established by the employer's safety management concept as an option when a fire has grown too large (see Purser \& Bensilum, 2001; Tancogne-Dejean \& Laclémence, 2016). Additionally, people need to be able to correctly judge whether an emergency call is necessary or whether a fire can be handled without professional help. Again, this is best taught through practical examples and exercises in which existing organisational safety management concepts are practically applied and implemented. From the participants' point of view, the main skills they thought they needed were calmness, an overview of the situation, fire-extinguishing knowledge, risk assessment skills and self-confidence (see Appendix E). Based on our initial findings, we think that all those aspects can be successfully trained, as our experiment shows that repetition (which usually would take place during training) leads to a significant decrease of perceived stress and danger (therefore greater calmness) and an increase in behavioural control (associated with greater self-confidence). In addition to practical exercises, training may also include theoretical concepts defined in the fire safety management concept, to deepen fire-extinguishing knowledge and risk assessment skills of employees. In principle, as in professional firefighter education, the success of such trainings for laypersons should be evaluated (see Niemann \& Thielsch, in press).

Finally, the applied fire extinguisher spray proved to be highly usable, as most participants were able to recognize and handle it directly without any prior instruction. This was probably because it is designed to work the same as any other typical spray known to laypersons (such as hairspray or paint spray) and is thus easy to use. Still, some participants did not recognize the fire extinguisher spray or had problems opening it (see Appendix E). It is, therefore, important to familiarize people with such an extinguishing agent, for example during regular fire safety trainings at the workplace or other forms of general safety instructions.

\section{Conclusion}

Laypersons are willing and able to successfully fight an incipient fire. However, their behaviour is not optimal and could lead to a certain amount of self-endangerment. The present experiment shows many positive exercise effects and offers several suggestions for the design of practical fire protection training courses for laypersons. From a theoretical perspective, future research of the applicability of the TPB in this field is promising. Moreover, the current findings emphasize the importance of the closely related construct selfefficacy and its strong effect on behaviour. 


\section{Acknowledgments}

First of all, we would like to thank Dirk Oberhagemann (German Fire Protection Association) for initiating this project and his active and extensive support during the field phase. Furthermore, we would like to thank Britta Weckenbrock and Zwanette Wüppen for their help in preparing materials for the experimental setup. For his steady assistance during the experiment, we thank Marvin Schetter. We thank Tabea Jaquet and Alexandra Razlaw for the effort they put into the coding of the interview data. And finally, we thank Guido Hertel for his valuable feedback on the study as well as Celeste Brennecka and the two anonymous reviewers for their very helpful comments on earlier versions of this manuscript.

\section{Declaration of interest statement}

The authors declare that they have no competing interests.

\section{References}

Amodeo, K. L., \& Nickelson, J. (2020). Predicting Intention to be Physically Active among Volunteer Firefighters. American Journal of Health Education, 51(1), 1-13.

Ajzen, I. (1985). From intentions to actions: A theory of planned behaviour. In Action control (pp. 11-39). Springer, Berlin, Heidelberg.

Ajzen, I. (1991). The theory of planned behaviour. Organizational behaviour and human decision processes, 50(2), 179-211.

Ajzen, I. (2002). Perceived behavioural control, self-efficacy, locus of control, and the theory of planned behaviour. Journal of Applied Social Psychology, 32(4), 665-683. https://doi.org/10.1111/j.1559-1816.2002.tb00236.x

Azjen, I., \& Fishbein, M. (1980). Understanding attitudes and predicting social behaviour. Englewood Cliffs. N.J.: Prentice Hall

Armitage, C. J., \& Conner, M. (2001). Efficacy of the theory of planned behaviour: A metaanalytic review. British journal of social psychology, 40(4), 471-499.

Baker, J., Bouchlaghem, D., \& Emmitt, S. (2013). Categorisation of fire safety management: Results of a Delphi Panel. Fire Safety Journal, 59, 37-46. doi:10.1016/j.firesaf.2013.03.005

Bandura, A. (1977). Self-efficacy: toward a unifying theory of behavioural change. Psychological review, 84(2), 191.

Bandura, A. (1982). Self-efficacy mechanism in human agency. American psychologist, $37(2), 122$.

Bandura, A. (1991). Social cognitive theory of self-regulation. Organizational behaviour and human decision processes, 50(2), 248-287.

Bauordnung für das Land Nordrhein-Westfalen [Building regulations for the state of North Rhine Westphalia], SGV NRW, §14 (2018). Retrieved 16 July 2020 from https://recht.nrw.de/lmi/owa/br_text_anzeigen?v_id=74820170630142752068.

Barnett, M., Bruck, D., \& Jago, A. (2007). Mean annual probability of having a residential fire experience throughout a lifetime: development and application of a methodology. Fire Safety Science, 7, 85-85. 
Beierlein, C., Kovaleva, A., Kemper, C.J. \& Rammstedt, B. (2012). Ein Messinstrument zur Erfassung subjektiver Kompetenzerwartungen. Allgemeine Selbstwirksamkeit Kursskala (ASKU). "[A measuring instrument for assessing subjective expectations of competence. General self-efficacy short scale (ASKU)]." GESIS-Working Papers $2012,17,5-24$.

Beierlein, C., Kovaleva, A., Kemper, C.J. \& Rammstedt, B. (2014). Eine Single-Item-Skala zur Erfassung von Risikobereitschaft: Die Kurzskala Risikobereitschaft-1 (R-1). "[ A single item scale for measuring risk appetite: The short scale Risk Appetite 1 (R-1)]." GESIS-Working Papers 2014, 34, 3-25.

Bonny, J. W., Leventon, I. T. (2020). Measuring human perceptions of developing room fires: The influence of situational and dispositional factors. Fire and Materials, 1-11. doi:10.1002/fam.2857

Byeon, D. H. (2019). Effect of fire safety education based on the theory of planned behaviour on the fire safety behaviour of care worker trainees. Fire Science and Engineering, 33(1), 147-155

Cimolino, U., Fuchs, M., Ridder, A. \& Südmersen, J. (2018). Innenangriff. "[Internal Attack]."Landsberg am Lech: ecomed Sicherheit,

Cohen J. E. (1988). Statistical Power Analysis for the Behavioural Sciences. Hillsdale, NJ: Lawrence Erlbaum Associates, Inc.

Cordeiro, E., Coelho, A. L., Rosetti, R. J. F., \& Almeida, J. (2011). Human behaviour under fire situations - Portuguese population. Proceedings of the Fire and Evacuation Modeling Technical Conference 2011 Baltimore, Maryland, August 15-16, 2011

Felfe, J., Six B., Schmook, R. \& Knorz, C. (2014). Commitment Organisation, Beruf und Besch ftigungsform (COBB). "[Commitment Organisation, profession and form of employment (COBB)].“ In D. Danner \& A. Glöckner-Rist (Eds.), Zusammenstellung sozialwissenschaftlicher Items und Skalen. doi:10.6102/zis9

Flanagan, J. C. (1954). The critical incident technique. Psychological bulletin, 51(4), 327.

Fritz, M. S. \& MacKinnon, D. P. (2007). Required sample size to detect the mediated effect. Psychol Sci., 18(3), 233-239.

Gerges, M., Mayouf, M., Rumley, P., \& Moore, D. (2017). Human behaviour under fire situations in high-rise residential building. International Journal of Building Pathology and Adaptation, 35(1), 90-106. https://doi.org/10.1108/IJBPA-09-20160022

Graham, T. L., \& Roberts, D. J. (2000). Qualitative overview of some important factors affecting the egress of people in hotel fires. International Journal of Hospitality Management, 19(1), 79-87.

Gwynne, S., Galea, E. R., Lawrence, P. J., \& Filippidis, L. (2001). Modelling occupant interaction with fire conditions using the buildingEXODUS evacuation model. Fire Safety Journal, 36(4), 327-357.

Hall, J. R. (2004). How many people can be saved from home fires if given more time to escape?. Fire Technology, 40(2), 117-126.

Höffchen, B. \& Lücking, D., (2005). Feuerwehr-Grundausbildung. "[Fire brigade basic training]"." Stuttgart: Verlag W. Kohlhammer 
Holborn, P. G., Nolan, P. F., \& Golt, J. (2004). An analysis of fire sizes, fire growth rates and times between events using data from fire investigations. Fire Safety Journal, 39(6), 481-524. https://doi.org/10.1016/j.firesaf.2004.05.002

Hoyle, R. H., Stephenson, M. T., Palmgreen, P., Pugzles Lorch, E. \& Donohew, R. L. (2002). Reliability and validity of a brief measure of sensation seeking. Personality and Individual Differences, 32(3), 401-414. doi:10.1016/S0191-8869(01)00032-0

Hulse, L. M., Galea, E. R., Thompson, O. F., \& Wales, D. (2020). Perception and recollection of fire hazards in dwelling fires. Safety Science, 122, 104518. doi: 10.1016/j.ssci.2019.104518

J ger, R. (2004). Konstruktion einer Ratingskala mit Smilies als symbolische Marken. "[Construction of a Rating Scale with Smilies as Symbolic Labels]." Diagnostica, 50(1), 31-38. doi:10.1026/0012-1924.50.1.31

Kerber, S. (2012). Analysis of Changing Residential Fire Dynamics and Its Implications on Firefighter Operational Timeframes. Fire Technology, 48, 865-891. doi:10.1007/s10694-011-0249-2

Kinateder, M. T., Kuligowski, E. D., Reneke, P. A., \& Peacock, R. D. (2014). A review of risk perception in building fire evacuation. National Institute of Standards and Technology.

Kobes, M., Helsloot, I., De Vries, B., \& Post, J. G. (2010). Building safety and human behaviour in fire: A literature review. Fire Safety Journal, 45(1), 1-11.

Krumm, S., Grube, A. \& Hertel, G. (2013). The Munster Work Value Measure. Journal of Managerial Psychology, 28(5), 532-560. doi:10.1108/JMP-07-2011-0023

Kuligowski, E. (2013). Predicting human behaviour during fires. Fire Technology, 49(1), 101-120.

Kunkelmann, J. (2003). Flashover / Backdraft - Ursachen, Auswirkungen, Gegenmaßnahmen. Forschungsbericht Nr. 130, Forschungsstelle für Brandschutztechnik am Karlsruher Institut für Technologie (KIT). "[Flashover / Backdraft - Causes, Effects, Countermeasures. Research Report No. 130, Research Center for Fire Protection Technology at the Karlsruhe Institute of Technology (KIT)]." Retrieved 12 March 2020 from http://www.ffb.kit.edu/download/IMK_Ber._Nr._130.pdf

Kunkelmann, J., \& Brein, D. (2010). Feuerwehreinsatztaktische Problemstellungen bei der Brandbekämpfung in Gebäuden moderner Bauweise. "[Fire brigade tactical problems in fire fighting in modern buildings]." Brandschutzforschung der Bundesländer der Bundesrepublik Deutschland, Bericht, (154).

Lesage, F. X. \& Berjot, S. (2011). Validity of occupational stress assessment using a visual analogue scale. Occupational Medicine, 61, 434-436. doi:10.1093/occmed/kqr037

Lewis, J.R. Utesch, B. \& Maher, D.E. (2015). Investigating the Correspondence Between UMUX -LITE and SUS Scores. In A. Marcus (Ed.): User Experience and Usability: Design Discourse, 204-211. Springer: Cham.

Mentrikoski, J. M., Duncan, C. L., Enlow, P. T., \& Aballay, A. M. (2019). Predicting Adolescents' Intentions to Engage in Fire Risk Behaviors: An Application of the Theory of Planned Behavior. Burns, 45, 1242-1250. doi: 10.1016/j.burns.2019.02.006 
Mohiyeddini, C., \& Bauer, S. (2007). Intentions-Verhaltens-L cke bei sportlichen Aktivit ten. "[Intention-behaviour gap in sports activities]." Zeitschrift für Sportpsychologie, 14(1), 3-13.

Niemann, L. \& Thielsch, M. T. (in press). Evaluation of Basic Trainings for Rescue Forces. Journal of Homeland Security and Emergency Management. https://doi.org/10.1515/jhsem-2019-0062

Orazulike, U. (2015). Making Them Pay: A Proposal to Expand Employer Responsibility for Occupational Safety and Health. SAGE Open. doi:10.1177/2158244015603891

Occupational Safety and Health Act 3088 (revised 2001) (United States). Retrieved 13 July 2020 from https://www.osha.gov/Publications/osha3088.html

Plattner, H.-P. (2004). Führen im Einsatz. „,[Leading an operation]“ Verlag W. Kohlhammer, Stuttgart.

Proulx, G. (1993). A stress model for people facing a fire. Journal of Environmental Psychology, 13(2), 137-147.

Proulx, G. (2001). Occupant behaviour and evacuation. Proceedings of the 9th International Fire Protection Symposium, Munich, May 25-26, 2001, pp. 219-232

Pulm, M. (2018). Falsche Taktik - Große Schäden. „[Wrong tactics - major damage].“ Stuttgart: Verlag W. Kohlhammer.

Purser, D. A., \& Bensilum, M. (2001). Quantification of behaviour for engineering design standards and escape time calculations. Safety science, 38(2), 157-182.

Rhodes, R. E., \& de Bruijn, G. J. (2013). How big is the physical activity intention-behaviour gap? A meta - analysis using the action control framework. British journal of health psychology, 18(2), 296-309. doi: 10.1111/bjhp.12032

Rodewald, G. \& Rempe, A. (2005). Feuerlöschmittel. "[Fire extinguishing agents]". Stuttgart: Verlag W. Kohlhammer.

Schallberger, U. (2005). Kurzskalen zur Erfassung der Positiven Aktivierung, Negativen Aktivierung und Valenz in Experience Sampling Studien (PANAVA-KS). "[ Short scales for recording positive activation, negative activation and valence in experience sampling studies (PANAVA-KS)].“ Zürich: Fachrichtung Angewandte Psychologie des Psychologischen Instituts der Universität.

Schott, L. \& Ritter, M. (2018). Aktuelles Grundwissen für den Dienst in der Feuerwehr. "[ Current basic knowledge for the service in the fire brigade]." Wenzel Verlag, Marburg.

Schupp, J. \& Gerlitz, J.-Y. (2005). Zur Erhebung der Big-Five-basierten Persönlichkeitsmerkmale im SOEP: Dokumentation der Instrumententwicklung BFI-S auf Basis des SOEP-Pretests 2005. "[For the survey of Big Five-based personality traits in SOEP: Documentation of the BFI-S instrument development based on the SOEP pre-test 2005].” Research Notes 4, 1-34.

Sommer, M. \& Nj , O. (2011). Learning amongst Norwegian fire - fighters. Journal of Workplace Learning, 23(7), 435-455. doi: 10.1108/13665621111162963 
Steinmetz, H., Knappstein, M., Ajzen, I., Schmidt, P., \& Kabst, R. (2016). How effective are behaviour change interventions based on the theory of planned behaviour?. Zeitschrift für Psychologie.

Szrajda, J., Tudorowska, M., Kujawski, S., Weber-Rajek, M., Sygit-Kowalkowska, E., Kobos, Z., Słomko, J., Tafil-Klawe, M. \& Zalewski, P. (2017). The Big Five personality and temperamental traits and its correlation with styles of coping with stress in the fire brigade officers. Journal of Education Culture and Society, 8(2), 163173. doi:10.15503/jecs20172.163.173

Tancogne-Dejean, M., \& Laclémence, P. (2016). Fire risk perception and building evacuation by vulnerable persons: Points of view of laypersons, fire victims and experts. Fire safety journal, 80, 9-19.

Thompson, O. F., Edwin, R. G., \& Hulse, L. M. (2018). A review of the literature on human behaviour in dwelling fires. Safety Science, 109, 303-312. doi:10.1016/j.ssci.2018.06.016

The Regulatory Reform (Fire Safety) Order (2005), §8 (UK). Retrieved 13 July 2020 from https://www.legislation.gov.uk/uksi/2005/1541/article/8/made

Wagner, S. L., Martin, C. A. \& McFee, J. A. (2009). Investigating the "rescue personality". Traumatology, 15(3), 5-12. doi:10.1177/1534765609338499

Welbourne, J., \& Booth-Butterfield, S. (2005). Using the theory of planned behaviour and a stage model of persuasion to evaluate a safety message for firefighters. Health communication, 18(2), 141-154.

Wood, P. G. (1972). The behaviour of people in fires. Fire Research Note No. 953, Fire Research Station. 
Fight or flight? Behaviour and experiences of laypersons in the face of an incipient fire

\begin{abstract}
APPENDIX
Appendix A: Detailed description of measures

The measuring instruments used are described in detail below, further information can be found in codebook (available at https://doi.org/10.5281/zenodo.3753931). Unless explicitly stated otherwise, a 7-point Likert scale ranging from "do not agree at all (1)" to "fully agree (7)" was used.
\end{abstract}

Intention of action. Since we found no established scale to measure the intention of action in an emergency situation, items were constructed by the authors. Participants were presented with five different options for action on the item "If I saw a small fire, I would...". Namely, these options were to try extinguishing it themselves; to not become active until rescue services arrive; to keep their distance and get to a safe place; to call for rescue services only; or to not do anything at all.

Attitude. Following Ajzen and Fishbein (1980) and Mohiyeddini \& Bauer (2007), attitudes were measured using a 7-step semantic differential. For this purpose, an adjective list (item 1: important - unimportant, item 2: useless - necessary, item 3: promising - doomed to failure), following the item anchor: "I think it is ... to extinguish an incipient fire." was presented to participants. Mohiyeddini \& Bauer (2007) report a Cronbach's $\alpha$ of .94 for their three-item scale.

Subjective norm. As reported in Mohiyeddini \& Bauer (2007), two items were constructed to assess the perceived subjective norm towards extinguishing fires at the workplace, such as "I believe that people in my professional environment would expect me to extinguish a small fire myself." Mohiyeddini \& Bauer (2007) report a Cronbach's $\alpha$ of .96 for this scale.

Perceived behavioural control. A two-item scale was used based on Mohiyeddini \& Bauer's (2007). Participants were asked to indicate their agreement with, for example, the following Item: "I have control over whether or not I can extinguish a small fire myself.". The reported Cronbach's $\alpha$ in Mohiyeddini \& Bauer (2007) for this scale is .83.

Self-efficacy (Allgemeine Selbstwirksamkeit Kurzskala (ASKU); Beierlein et al., 2012). The three item scale (e.g., "In difficult situations I can rely on my abilities.") was used to assess Self-efficacy expectations. Beierlein et al. (2012) provided evidence for reliability (Cronbach's $\alpha=.81$ to .86 ) and convergent validity of their measure. 
Risk appetite. (R-1; Beierlein et al., 2014) The single-item scale asks participants indicate how willing they are to take risks in general ("Please assess yourself personally: How willing are you to take risks in general?") on a 7 point Likert scale ranging from 1 (not willing to take risks at all) to 7 (very risk-taking). Retest reliability has been demonstrated by Beierlein et al. (2014) across several studies $(r=.74)$.

Sensation seeking (Brief sensation seeking scale (BSSS); Hoyle et al., 2002). In order to investigate participant's individual degree of sensation seeking, the 6-Item scale (e.g., "I get restless when I spend too much time at home") was translated into German. Hoyle et al., (2002) report a Cronbach's $\alpha$ of .68 to .79 for their scale.

Organizational commitment („Commitment Organisation, Beruf und Beschäftigungsform $\left(\mathrm{COBB}^{\prime \prime}\right)$; Felfe, Six, Schmook, \& Knorz, 2014)". The subscale "affective commitment [affektives Commitment]" from the "Identification with profession and work [Identifikation mit Beruf und Tätigkeit,]" scale was used. Participants were asked to indicate their agreement with 7 items like "It is of great importance for me to practice exactly this profession". Felfe et al. (2014) reported Cronbach's $\alpha=.91$ for the affective dimension scale used in this study.

Personality (BFI-S; Schupp \& Gerlitz, 2014). The BFI-S is a widely used measure to assess the "big five" personality traits (extraversion, neuroticism, conscientiousness, agreeableness, openness to experience). Reliability for all scales has been checked, the reported Cronbach's $\alpha$ varies between .53 to .74 for the five different dimensions.

Motives (Muenster Work Value Scale; Krumm et al., 2013). In the German version of the "Muenster Work Value Scale", participants were asked to put 21 motives into a hierarchical order, according to the relative importance of each value. This measure consists of the four following scales: intrinsic growth value \& affective value (e.g., "self-realization"), generativity values (e.g., "legacy"), extrinsic growth values (e.g., "status") and contextrelated values (e.g., "stability"). Krumm et al. (2013) report a retest reliability of $r=.75$.

Stress. The subjective stress perception of participants was measured by means of a visual analogue scale (VAS; e.g., Lesage \& Berjot, 2011). The scale had two poles that were labelled "not stressful at all" to "very stressful". The validity of the measure was demonstrated by comparing the values of the VAS with another established measure of stress: Lesage and Berjot (2011) report a correlation coefficient of $r=0.68$ between the stress VAS and the PSS14.

Danger assessment. Subjective danger assessment was measured on a VAS as well. Participants were asked to indicate as how dangerous they experienced the trial, ranging from "not dangerous at all" to "very dangerous". The assessment was based on Proulx's stress model (1993).

Mood. Mood was measured with a graphical five-point smiley scale ranging from a very sad 
to a very happy smiley (Jäger, 2004). In a series of two studies, Jäger (2004) provided evidence for the unidimensionality and equidistance of this scale as well as high correlations with the German version of the PANAS scale $(.75 \leq r \leq .89)$.

General emotional state. In order to measure the general emotional state of participants, positive and negative activation was assessed using the PANAVA-KS (Schallberger, 2005). Participants were asked to rate their positive and negative activation as well as valence on 8 bipolar items on a 7-point scale (e.g., ranging from "stressed" to "relaxed"). Schallberger et al. (2005) report a reliability of Cronbach's $\alpha$ ranging from $\alpha=.74$ to $\alpha=.83$ for the three subscales.

Satisfaction. Satisfaction was assessed by asking participants to rate their satisfaction with their performance in each of the two trails on a 7-point Likert scale ranging from "very dissatisfied (1)" to "very satisfied (7)".

Usability. To assess usability of the used fire extinguishing spray, the two-item scale "UMUX-Lite" (Lewis et al., 2015), consisting of the positive tone items of the "UMUX" (Lewis, 2015), was adapted (items: "The capabilities of the fire extinguisher spray meet my requirements." and "I found the fire extinguisher spray easy to use."). Lewis et al. (2015) report a reliability of Cronbach's $\alpha=.86$ for the original scale. Furthermore, concurrent validity was proven by correlation with the SUS and ratings of likelihood-to-recommend (respectively, $r=.83$ and $r=.72$ ).

Manipulation checks. To assess whether or not the manipulation of the two experimental conditions (big/small pillow and repetition of trial) were successful, participants were asked to rate their agreement with the following three statements: "I perceived the fire I was confronted with as big."; "The second time I tried to extinguish the fire, I felt safer."; and "The handling of the spray during the second extinguishing attempt was easier for me." In addition, the level of experienced reality was assessed. Perceived reality of the experiment was assessed with four newly created specific items such as "I felt the situation was realistic." 


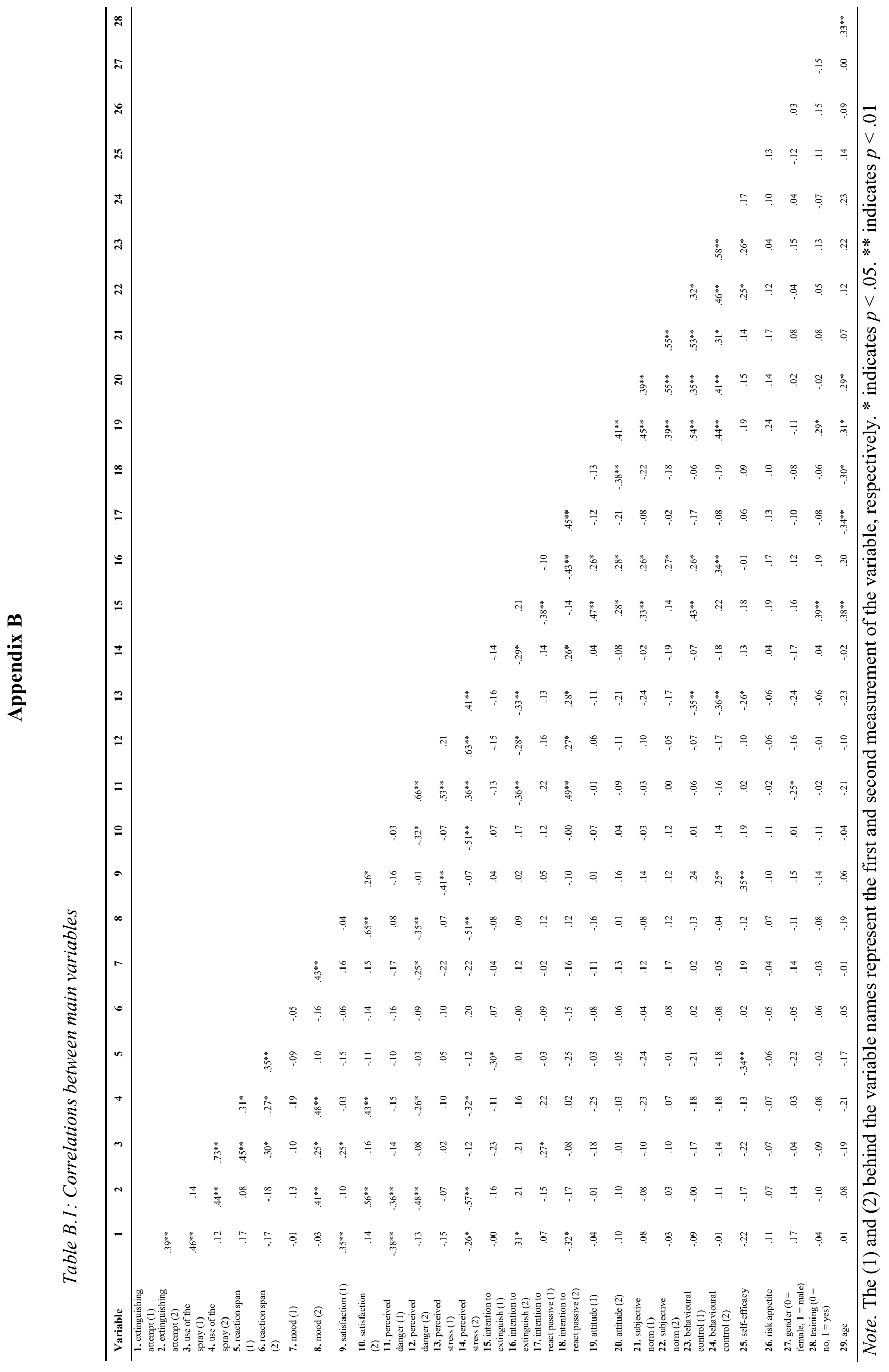




\section{Appendix C}

Table C.1: Means, standard deviations, and reliabilities (if applicable, standardized Cronbach's $\alpha$ ) of scales

\begin{tabular}{|c|c|c|c|}
\hline Variable & $M$ & $S D$ & $\alpha$ \\
\hline Reaction time span (1) & 17.93 & 10.17 & \\
\hline Reaction time span (2) & 12.16 & 4.15 & \\
\hline Mood (1) & 3.97 & 0.64 & \\
\hline Mood (2) & 4.23 & 0.77 & \\
\hline General emotional state (positive activation) & 5.73 & 0.66 & .72 \\
\hline General emotional state (negative activation) & 2.92 & 1.16 & .84 \\
\hline Satisfaction (1) & 5.38 & 1.54 & \\
\hline Satisfaction (2) & 6.03 & 1.15 & \\
\hline Perceived danger (1) & 3.43 & 2.21 & \\
\hline Perceived danger (2) & 2.70 & 2.28 & \\
\hline Perceived stress (1) & 3.54 & 2.30 & \\
\hline Perceived stress (2) & 2.24 & 1.85 & \\
\hline Intention to extinguish (1) & 6.31 & 0.94 & \\
\hline Intention to extinguish (2) & 6.46 & 0.82 & \\
\hline Intention to react passive (1) & 3.80 & 1.48 & 0.53 \\
\hline Intention to react passive (2) & 3.15 & 1.42 & 0.60 \\
\hline Attitude (1) & 4.31 & 0.71 & 0.86 \\
\hline Attitude (2) & 5.83 & 0.62 & 0.77 \\
\hline Subjective norm (1) & 5.26 & 1.12 & 0.79 \\
\hline Subjective norm (2) & 5.68 & 1.10 & 0.77 \\
\hline Behavioural control (1) & 5.24 & 1.12 & 0.67 \\
\hline Behavioural control (2) & 5.98 & 0.82 & 0.50 \\
\hline Self-efficacy & 5.80 & 0.77 & 0.87 \\
\hline Risk appetite & 3.98 & 1.30 & \\
\hline Age & 33.84 & 13.20 & \\
\hline Usability & 6.54 & 0.84 & 0.62 \\
\hline Perceived Realism & 5.86 & 0.87 & 0.62 \\
\hline
\end{tabular}

Note. $M$ and $S D$ are used to represent mean and standard deviation, respectively. The (1) and (2) behind the variable names represent the first and second measurement of the variable, respectively. $\mathrm{N}$ $=64$. 


\section{Appendix D}

Table D.1: Regression results using the general intention to extinguish an incipient fire (measured in the pre-test) as the criterion

\begin{tabular}{lccccc}
\hline Predictor & $\beta$ & $\beta 95 \% \mathrm{KI}$ & $S E$ & $r$ & Fit \\
\hline Attitude & $0.38^{*}$ & {$[0.01,0.76]$} & 0.19 & $.46^{* *}$ & \\
Subjective norm & 0.04 & {$[-0.20,0.28]$} & 0.12 & $.31^{*}$ & \\
Behavioural control & 0.20 & {$[-0.06,0.46]$} & 0.13 & $.43^{* *}$ & \\
Self-efficacy & 0.04 & {$[-0.25,0.34]$} & 0.15 & .16 & \\
Risk appetite & 0.06 & {$[-0.11,0.24]$} & 0.09 & .17 & \\
& & & & & $R^{2}=.265, F(5,56)=4.04$, \\
& & & & & $p<.01 * *$ \\
\hline
\end{tabular}

Note. $\beta=$ beta weights of the predictors, $\beta 95 \% \mathrm{KI}=95 \%$ confidence intervals of the beta weights, $\mathrm{SE}=$ standard error of the beta weights, $r=$ bivariate correlations according to Pearson with the criterion. Significance: $* p<.05, * * p<.01$.

Table D.2: Regression results using behaviour (reaction time span) as the criterion

\begin{tabular}{lllrlc}
\hline Predictor & \multicolumn{1}{c}{$\beta$} & \multicolumn{1}{c}{$\beta 95 \% \mathrm{KI}$} & $S E$ & \multicolumn{1}{c}{$r$} & \multicolumn{1}{c}{ Fit } \\
\hline Behavioural control & -0.45 & {$[-3.03,2.13]$} & 1.29 & -.21 & \\
Self-efficacy & $-3.66^{* *}$ & {$[-7.12,-0.19]$} & 1.72 & $-.32 *$ & \\
Intention to extinguish & -2.40 & {$[-5.32,0.53]$} & 1.46 & $-.29 *$ & \\
& & & & & $R^{2}=.162, F(3,54)=3.50$, \\
& & & & & $p<.05 *$ \\
\hline
\end{tabular}

Note. $\beta=$ beta weights of the predictors, $\beta 95 \% \mathrm{KI}=95 \%$ confidence intervals of the beta weights, $\mathrm{SE}=$ standard error of the beta weights, $r=$ bivariate correlations according to Pearson with the criterion. Significance: $* p<.05$. 
Table D.3: Explorative regression results using the general intention to extinguish an incipient fire (measured in the pre-test) as the criterion

\begin{tabular}{lccccc}
\hline Predictor & $\beta$ & $\beta 95 \% \mathrm{KI}$ & $S E$ & $r$ & Fit \\
\hline Attitude & 0.29 & {$[-0.09,0.67]$} & 0.19 & $.46^{* *}$ & \\
Subjective norm & 0.09 & {$[-0.14,0.32]$} & 0.11 & $.31^{*}$ & \\
Behavioural control & 0.11 & {$[-0.14,0.36]$} & 0.12 & $.43^{* *}$ & \\
Self-efficacy & 0.07 & {$[-0.21,0.35]$} & 0.14 & .16 & \\
Risk appetite & 0.06 & {$[-0.11,0.22]$} & 0.08 & .17 & \\
Age & 0.01 & {$[-0.00,0.03]$} & 0.01 & $.38^{* *}$ & \\
Past training & $0.58^{*}$ & {$[0.04,1.11]$} & 0.27 & $.37 * *$ & \\
Gender & 0.38 & {$[-0.07,0.83]$} & 0.22 & .15 & \\
& & & & & $R^{2}=.405, F(8,53)=4.51$, \\
& & & & & $p<.001 * * *$ \\
\hline
\end{tabular}

Note. $\beta=$ beta weights of the predictors, $\beta 95 \% \mathrm{KI}=95 \%$ confidence intervals of the beta weights, $\mathrm{SE}=$ standard error of the beta weights, $r=$ bivariate correlations according to Pearson with the criterion. Significance: $* p<.05, * * p<.01, * * * p<.001$.

Table D.4: Explorative regression results using behaviour (reaction time span) as the criterion

\begin{tabular}{llllll}
\hline Predictor & \multicolumn{1}{c}{$\beta$} & \multicolumn{1}{c}{$\beta 95 \% \mathrm{KI}$} & $S E$ & \multicolumn{1}{c}{$r$} & \multicolumn{1}{c}{ Fit } \\
\hline Behavioural control & 0.08 & {$[-2.55,2.70]$} & 1.31 & -.21 & \\
Self-efficacy & $-3.97^{* *}$ & {$[-7.45,-0.49]$} & 1.73 & $-.32^{*}$ & \\
Intention to extinguish & -2.43 & {$[-5.70,0.84]$} & 1.63 & $-.29 *$ & \\
Age & -0.06 & {$[-0.29,0.16]$} & 0.11 & -.15 & \\
Past training & 2.75 & {$[-4.51,10.01]$} & 3.62 & .02 & \\
Gender & -4.47 & {$[-9.93,0.99]$} & 2.72 & -.23 & $R^{2}=.223, F(6,51)=2.43$, \\
& & & & & $p<.05 *$ \\
\hline
\end{tabular}

Note. $\beta=$ beta weights of the predictors, $\beta 95 \% \mathrm{KI}=95 \%$ confidence intervals of the beta weights, $\mathrm{SE}=$ standard error of the beta weights, $r=$ bivariate correlations according to Pearson with the criterion. Significance: $* p<.05$. 


\section{Appendix E}

Two independent observers coded the interview data, and potential misunderstandings were discussed between observers in a second round. Afterwards, intercoder reliability of the built categories was calculated using Cohens $\kappa$ : values $<0$ indicate no agreement, $0-0.20$ slight agreement, $0.21-0.40$ fair agreement, $0.41-0.60$ moderate agreement, $0.61-0.80$ substantial agreement, and 0.81-1 almost perfect agreement (Landis and Koch, 1977). The following tables contain the results regarding the six interview questions asked after the first trial. Question 1: Before the extinguishing, did you make a plan how you were going to
proceed? [have it described]

Table E.1: Description/content of plan

\begin{tabular}{|c|c|c|c|}
\hline Category & $\begin{array}{c}\text { \# of } \\
\text { statements }\end{array}$ & $\%$ & Sample statement \\
\hline Exploring the situation & 32 & 33.0 & $\begin{array}{l}\text { I first looked around the room and } \\
\text { checked the possibilities. }\end{array}$ \\
\hline $\begin{array}{l}\text { Use of fire } \\
\text { extinguisher spray }\end{array}$ & 28 & 28.9 & $\begin{array}{l}\text { And then I saw this extinguishing } \\
\text { spray and the plan was that I could } \\
\text { extinguish the fire with it. }\end{array}$ \\
\hline No planning & 13 & 13.4 & A plan. No, I haven’t. \\
\hline $\begin{array}{l}\text { Use of alternative } \\
\text { extinguishing method }\end{array}$ & 7 & 7.2 & $\begin{array}{l}\text { I know that you can suffocate fire. I } \\
\text { was looking for a jacket, that would } \\
\text { have been my first choice. }\end{array}$ \\
\hline Securing & 6 & 6.2 & $\begin{array}{l}\text { I've searched everywhere to check } \\
\text { if I had to save anything. Like, any } \\
\text { living beings or anything else. }\end{array}$ \\
\hline $\begin{array}{l}\text { Remove burning } \\
\text { object from the site }\end{array}$ & 5 & 5.2 & $\begin{array}{l}\text { And then I checked if I can get to it } \\
\text { carefully and just put it down. }\end{array}$ \\
\hline Emergency call & 3 & 3.1 & First call the emergency. \\
\hline Escape smoke & 3 & 3.1 & $\begin{array}{l}\text { I saw where the smoke was going } \\
\text { and stood on the other side so I } \\
\text { didn't inhale the smoke directly. }\end{array}$ \\
\hline
\end{tabular}

Note. Multiple statements were possible if a plan was made, 97 statements were given.

Cohens $\kappa=.85$ 
Question 2: What did you think or how did you feel when you tried to put out the fire?

Table E.2: Thoughts of participants

\begin{tabular}{lccl}
\hline Category & $\begin{array}{c}\text { \# of } \\
\text { statements }\end{array}$ & $\%$ & \multicolumn{1}{c}{ Sample statement } \\
\hline Goal setting & 20 & 50.0 & $\begin{array}{l}\text { And then I focused on this spray and thought } \\
\text { I'd take it step by step. } \\
\text { I first checked to see if there were any } \\
\text { possibilities to extinguish it. } \\
\text { Orientation }\end{array}$ \\
$\begin{array}{l}\text { Alternatives to the } \\
\text { extinguishing agent }\end{array}$ & 4 & 145.0 & $\begin{array}{l}\text { I didn't think I could do it alone. I better call } \\
\text { the fire department. } \\
\text { But then the situation was already aborted } \\
\text { because I had said before that I would call } \\
\text { someone else. }\end{array}$ \\
Other & 2 & 5.0 &
\end{tabular}

Note. Multiple statements were possible, 40 statements were given. Cohens $\kappa=.79$

Table E.3: Emotions of participants

\begin{tabular}{|c|c|c|c|}
\hline Category & $\begin{array}{c}\text { \# of } \\
\text { statements }\end{array}$ & $\%$ & Sample statement \\
\hline Security & 27 & 34.6 & $\begin{array}{l}\text { And then I thought okay, I felt like I was } \\
\text { kind of in control. }\end{array}$ \\
\hline Insecurity & 17 & 21.8 & $\begin{array}{l}\text { Not so good. Unknown situation. I have } \\
\text { never had anything like this. }\end{array}$ \\
\hline Satisfaction & 15 & 19.2 & $\begin{array}{l}\text { But then somehow also satisfied that it } \\
\text { worked out. }\end{array}$ \\
\hline Stress & 12 & 15.4 & $\begin{array}{l}\text { I was just a little stressed about it, if it } \\
\text { works. I didn't know that. }\end{array}$ \\
\hline Fear & 6 & 7.7 & A little panic before extinguishing. \\
\hline Other & 1 & 1.3 & $\begin{array}{l}\text { I couldn't really try that much because I } \\
\text { didn't find anything. And I felt bad because } \\
\text { I wanted to delete it, but I couldn't. }\end{array}$ \\
\hline
\end{tabular}

Note. Multiple statements were possible, 78 statements were given. Cohens $\kappa=.86$ 
Question 3: What was particularly effective about your behaviour?

Table E.4: Effective behaviour from the viewpoint of participants

\begin{tabular}{lccl}
\hline Category & $\begin{array}{c}\text { \# of } \\
\text { statements }\end{array}$ & $\%$ & \multicolumn{1}{c}{ Sample statement } \\
\hline $\begin{array}{l}\text { Use of fire } \\
\text { extinguisher spray }\end{array}$ & 27 & 25.0 & $\begin{array}{l}\text { Saw the spray there and then extinguished it } \\
\text { (the fire) }\end{array}$ \\
$\begin{array}{l}\text { Quick reaction } \\
\text { Right. Well, I find the immediate response } \\
\text { effective. }\end{array}$ \\
$\begin{array}{l}\text { Exploration behaviour } \\
\text { Keeping calm }\end{array}$ & 18 & 16.7 & $\begin{array}{l}\text { First see what's available } \\
\text { Yes, I've just been so calm and level-headed. }\end{array}$ \\
$\begin{array}{l}\text { Goal setting } \\
\text { Use of alternative }\end{array}$ & 15 & 9.3 & $\begin{array}{l}\text { The order. Come in, look, overview, then } \\
\text { extinguish. }\end{array}$ \\
extinguishing method & 9 & 8.3 & $\begin{array}{l}\text { I think it was effective to just get help and } \\
\text { leave instead of putting myself in danger. }\end{array}$ \\
$\begin{array}{l}\text { Use of training } \\
\text { knowledge }\end{array}$ & 4 & 3.7 & $\begin{array}{l}\text { For me, that was most effective. } \\
\text { say, a great feeling of security. }\end{array}$ \\
\hline
\end{tabular}

Note. Multiple statements were possible, 108 statements were given. Cohens $\kappa=.87$ 
Question 4: What was not effective? How could you have acted alternatively?

Table E.5: Ineffective behaviour from the viewpoint of participants

\begin{tabular}{|c|c|c|c|}
\hline Category & $\begin{array}{c}\text { \# of } \\
\text { statements }\end{array}$ & $\%$ & Sample statement \\
\hline $\begin{array}{l}\text { Difficulties with fire } \\
\text { extinguisher spray }\end{array}$ & 16 & 20.0 & I couldn't open the [spray] bottle. \\
\hline Acting too slowly & 16 & 20.0 & $\begin{array}{l}\text { I think it might have been possible to grasp } \\
\text { the situation more quickly. }\end{array}$ \\
\hline $\begin{array}{l}\text { Fire extinguisher } \\
\text { spray not recognized }\end{array}$ & 11 & 13.8 & $\begin{array}{l}\text { Because in the first moment I actually did } \\
\text { not recognize the fire extinguisher, namely } \\
\text { the spray, as such. }\end{array}$ \\
\hline Self-endangerment & 9 & 11.3 & $\begin{array}{l}\text { Well, that I tried to move the fireplace, } \\
\text { instead of really thinking first, okay, how } \\
\text { can I extinguish it. That was definitely } \\
\text { ineffective. }\end{array}$ \\
\hline No goal setting & 9 & 11.3 & $\begin{array}{l}\text { So it wasn't so dangerous that the fire could } \\
\text { have done something somewhere else. }\end{array}$ \\
\hline Wrong decision to act & 8 & 10.0 & $\begin{array}{l}\text { I just liked having something to put over it. } \\
\text { That I would have just somehow. I was } \\
\text { looking for it all the time. }\end{array}$ \\
\hline Emotional reaction & 6 & 7.5 & $\begin{array}{l}\text { I panicked a little. Maybe I was a little } \\
\text { hectic. It may not have been as effective. } \\
\text { Maybe you could have thought about it a } \\
\text { little more calmly. }\end{array}$ \\
\hline $\begin{array}{l}\text { Missing orientation } \\
\text { behaviour }\end{array}$ & 5 & 6.3 & I didn't notice anything else. \\
\hline
\end{tabular}

Table E.6: Alternative behaviours from the viewpoint of participants

\begin{tabular}{|c|c|c|c|}
\hline Category & $\begin{array}{c}\text { \# of } \\
\text { statements }\end{array}$ & $\%$ & Sample statement \\
\hline Rational reaction & 17 & 50.0 & $\begin{array}{l}\text { Alternatively, I could have called the fire } \\
\text { department if there was more. }\end{array}$ \\
\hline $\begin{array}{l}\text { Stronger exploratory } \\
\text { behaviour }\end{array}$ & 13 & 38.2 & $\begin{array}{l}\text { I think I focused on that one fire source } \\
\text { pretty quick. Maybe there could have been a } \\
\text { second one, which I wouldn't have noticed } \\
\text { so quickly. }\end{array}$ \\
\hline $\begin{array}{l}\text { Better use of the } \\
\text { extinguishing agent }\end{array}$ & 3 & 8.8 & $\begin{array}{l}\text { Maybe hold the can a little bit more at the } \\
\text { top, so that it really reaches the fire. }\end{array}$ \\
\hline More goal setting & 1 & 2.9 & And then put the fire out where it is. \\
\hline
\end{tabular}

Note. Multiple statements were possible, 34 statements were given. Cohens $\kappa=.69$ 
Question 5: What do you think are the most important skills or qualities someone should have to extinguish an incipient fire of this kind in real life?

Table E. 7: Important skills and qualities from the viewpoint of participants

\begin{tabular}{|c|c|c|c|}
\hline Category & $\begin{array}{c}\text { \# of } \\
\text { statements }\end{array}$ & $\%$ & Sample statement \\
\hline Calmness & 40 & 30.5 & Keep calm. \\
\hline Overview & 23 & 17.6 & Always get an overview of the situation. \\
\hline $\begin{array}{l}\text { Fire-extinguishing } \\
\text { knowledge }\end{array}$ & 20 & 15.3 & $\begin{array}{l}\text { One should basically know how to use the } \\
\text { extinguishing agents. }\end{array}$ \\
\hline Risk assessment & 18 & 13.7 & Try to assess the situation, i.e., the danger. \\
\hline Self-confidence & 16 & 12.2 & One should not be afraid of fire. \\
\hline Ability to act & 12 & 9.2 & $\begin{array}{l}\text { The most important quality is that you do } \\
\text { something. That you get into action and you } \\
\text { don't stop and think for a long time. }\end{array}$ \\
\hline Other & 2 & 1.5 & Theoretically, even a child can do it. \\
\hline
\end{tabular}

Note. Multiple statements were possible, 131 statements were given. Cohens $\kappa=.88$ 